IZA DP No. 738

Managerial J ob Assignment and Imperfect

Competition in Asymmetric Equilibrium

Volker Grossmann

March 2003 


\title{
Managerial Job Assignment and Imperfect Competition in Asymmetric Equilibrium
}

\author{
Volker Grossmann \\ University of Zurich and IZA Bonn
}

\author{
Discussion Paper No. 738 \\ March 2003
}

\author{
IZA \\ P.O. Box 7240 \\ D-53072 Bonn \\ Germany \\ Tel.: +49-228-3894-0 \\ Fax: +49-228-3894-210 \\ Email: iza@iza.org
}

This Discussion Paper is issued within the framework of IZA's research area Mobility and Flexibility of Labor. Any opinions expressed here are those of the author(s) and not those of the institute. Research disseminated by IZA may include views on policy, but the institute itself takes no institutional policy positions.

The Institute for the Study of Labor (IZA) in Bonn is a local and virtual international research center and a place of communication between science, politics and business. IZA is an independent, nonprofit limited liability company (Gesellschaft mit beschränkter Haftung) supported by the Deutsche Post AG. The center is associated with the University of Bonn and offers a stimulating research environment through its research networks, research support, and visitors and doctoral programs. IZA engages in (i) original and internationally competitive research in all fields of labor economics, (ii) development of policy concepts, and (iii) dissemination of research results and concepts to the interested public. The current research program deals with (1) mobility and flexibility of labor, (2) internationalization of labor markets, (3) welfare state and labor market, (4) labor markets in transition countries, (5) the future of labor, (6) evaluation of labor market policies and projects and (7) general labor economics.

IZA Discussion Papers often represent preliminary work and are circulated to encourage discussion. Citation of such a paper should account for its provisional character. A revised version may be available on the IZA website (www.iza.org) or directly from the author. 
IZA Discussion Paper No. 738

March 2003

\section{ABSTRACT \\ Managerial Job Assignment and Imperfect Competition in Asymmetric Equilibrium*}

This paper develops a model with multiple market locations in which the quality of intangible assets of firms, provided by management, determines the firms' performance. Despite an ex ante symmetry of potential entrants, the equilibrium assignment of heterogeneous managerial skills to firms tends to be asymmetric. This sorting outcome determines both the goods market structure at single locations and the size distribution of firms. Results are consistent with a number of observed patterns regarding the size distribution of firms and establishments, and the relation of firm size to profitability, productivity, managerial skills and manager remuneration.

JEL Classification: D40, J31, L16

Keywords: asymmetric equilibrium, firm size, intangible assets, managerial job assignment

Volker Grossmann

University of Zurich

Socioeconomic Institute

Raemistr. 62

$\mathrm{CH}-8001$ Zurich

Switzerland

Tel.: +4116342288

Fax: +4116344996

Email: volker.grossmann@wwi.unizh.ch

\footnotetext{
* I am grateful to Johannes Binswanger and Josef Falkinger for detailed comments on previous versions of the paper. Moreover, I am indebted for helpful discussions to Tomer Blumkin, Armin Falk, Gilles Saint-Paul, John Sutton, and seminar participants at the University of Zurich and the Econometric Society European Meeting (ESEM) 2002, held in Venice.
} 


\section{Introduction}

In the industrialized world, intangible assets like organizational know-how, product design, trademarks and the internal human capital stock are key factors for the performance of firms. Development of intangible assets, e.g., through product design, organization of production, marketing and informal training of workers, is the responsibility of the management of a firm and gives rise to economies of scale and imperfect product markets. These observations suggest that there are important interactions between product market characteristics and the market for managerial skills. This paper develops a model which analyzes this interaction. By doing so, the model is capable to explain empirical regularities regarding the size distribution of firms and establishments, and the relation of firm size to profitability, productivity, managerial skills and manager remuneration in a unified framework.

The basic hypothesis of the model is that the quality of intangible assets depends on an (aggregate) index of managerial skills in firms. ${ }^{1}$ Firms set up head departments by hiring managers from a heterogeneous distribution of skills. Managerial wage costs for the development of intangible assets are endogenous and treated as sunk costs at the product market competition stage. There is free entry of firms into the economy and all potential entrants are ex ante identical. The economy has multiple market locations and entry into single markets is a prerequisite to participate in local product market competition. After the hiring of managers, firms choose the market range in which they operate, i.e., their number of plants or branches. Intangible assets are geographically non-rival, i.e., are common assets for firms in any market location they are active (e.g., Markusen (1995), Wong (1995)). However, there are "Coasian" diseconomies of scale in coordinating and governing single plants or branches (e.g., Williamson (1975), Porter (1986)).

According to the model, product markets and the market for managerial skills interact in the following way. On the one hand, the nature of product market

\footnotetext{
${ }^{1}$ Also quantitatively, managerial employment is important. According to Berman, Bound and Grilichis (1994, Tab. I), in U.S. manufacturing the employment share in managerial occupations was 10.9 percent in 1987, with rising tendency. See also Grossmann (2002).
} 
competition determines, for a given wage structure, the incentive of firms to hire managers with high skills. On the other hand, the sorting of managerial skills in firms determines both the goods market structure at single locations and the size distribution of firms. It is shown under which product market characteristics and technological conditions an asymmetric equilibrium assignment of managers to firms is obtained despite an ex ante symmetry of potential entrants. ${ }^{2}$

After analyzing the general structure of the model, both the results and the equilibrium concept are illustrated by specifying the nature of product market competition. In these examples, the quality of intangible assets is reflected by the perceived quality of goods or unit production costs. First, it is shown that under monopolistic competition à la Dixit and Stiglitz (1977), firms are completely segregated by managerial skill if the price elasticity of demand is sufficiently high, i.e., if product market competition is intense. The underlying reason is that, in this case, small differences in the quality of intangible assets become magnified in large profit differences, with greater magnification for higher quality levels. All other things equal, this leads to high incentives for firms to hire good managers, implying a symmetry-breaking feedback effect on the assignment of managerial skills to firms. This driving force towards asymmetry of managerial job assignment is also at work in a second example, which examines monopolistic competition under linear demand schedules (Ottaviano and Thisse (1999)).

The literature on assignment of heterogeneous workers to firms has recently gained renewed interest (e.g., Kremer (1993), Kremer and Maskin (1996), Saint-

\footnotetext{
${ }^{2}$ Related literature usually predicts that symmetry of potential entrants leads to symmetric free-entry equilibria. For instance, in standard versions of "love of variety" models of monopolistic competition (Spence (1976), Dixit and Stiglitz (1977)), "ideal variety" models (Lancaster (1979), Helpman (1981)) or "location" (spatial) models (Hotelling (1929), Salop (1979)) the number of active firms is determined by some exogenous entry costs and firms are ex post identical. An exception is Fishman and Rob (1999) who study a model with a given number of initially identical firms, in which cost shocks generate an asymmetric steady-state equilibrium. Another strand of literature are models of industry dynamics, which usually assume ex ante heterogeneous firms (e.g., Jovanovic (1982), Athey and Schmutzler (2001)). The present model may be viewed as complementary to this literature, explaining why firms differ in the first place.
} 
Paul (2001), Shimer and Smith (2000), Shimer (2001), Prat (2002)). This literature highlights the role of technological complementarity and spillovers among workers for a segregation of firms by their workers' skill. (For a comprehensive review of the less recent literature on job assignment, see Sattinger (1993).) In contrast, this paper derives asymmetric equilibria with respect to the sorting of skills from product market characteristics, by accounting for the role of intangible assets for the performance of firms.

The work of Rosen (1982) and Saint-Paul (2001) are most closely related to the present analysis. Saint-Paul (2001) shows that, by allowing for intra-firm spillovers when output of a homogenous good is a function of an aggregate skill index, typically, the equilibrium assignment of workers is segregated and the wage distribution skewed to the right. He applies his model to analyze the impact of new information technology on segmentation and wage inequality. Thus, his focus is very different from the present multi-market context in which managerial quality is the key to create valuable intangible assets and the sorting equilibrium depends on product market characteristics. Rosen (1982) examines the relationship between firm size, managerial job assignment and managerial wages by focussing on the supervisory role of management. In his analysis, good managers sort in large firms and receive high rewards because of a technological complementarity between supervising skills and the span of control. In contrast, in the present analysis, for firms to be large in the first place they have to attract good managers who create valuable intangible assets. Moreover, the present paper also studies the number of establishments as measure for firm size, in addition to output, sales or employment.

Results are consistent with the following patterns which are discussed in more detail at the end of this paper. (i) The size distribution of firms and plants within industries is highly skewed to the right (e.g., Sutton (1997)); (ii) both larger firms and firms with higher market shares are more profitable (e.g., Schmalensee, 1989); (iii) there is a substantial degree of heterogeneity among firms and establishments with respect to productivity levels, with larger firms and plants being more productive (e.g., Bartelsman and Doms (2000)); (iv) larger firms employ better workers (e.g., 
Troske (1999)), and, particularly, average managerial skill levels substantially differ across firms (e.g., O’Shaughnessy, Levine and Capelli (2001)); finally, (v) larger firms pay substantially higher managerial wages (e.g., Conyon and Murphy (2000)).

The paper is organized as follows. In section 2, the model is presented and its crucial assumptions are discussed. Section 3 defines the equilibrium and characterizes market ranges, profits, the assignment of managers and the measure of firms in equilibrium. Section 4 illustrates both the results and the equilibrium concept by specifying the nature of imperfect competition in the multiple goods markets. Section 5 shows how the results derived from the model relate to the observed patterns (i)-(v) above. Section 6 summarizes the main results. All proofs and extensive derivations are relegated to an appendix.

\section{The Model}

This section presents the model and discusses its main assumptions.

\subsection{Set Up}

Firms are characterized by intangible assets which affect the firms' productivity or (perceived) product quality, respectively. There is a large number of potential entrants in the economy and entry is free. Let $\mathcal{I}=[0, I]$ be the set of firms which actually enter. Firms are profit-maximizers.

Labor supply is inelastic and normalized to unity. Workers differ in their ability $h$ to develop intangible assets, called managerial skill level. Let $g(h)$ be the mass function of the distribution of skill supply, with support being the set $\mathcal{H}=$ $\left\{h^{0}, h^{1}, \ldots, h^{K}\right\}, 0 \leq h^{0}<h^{1}<\ldots<h^{K}<\infty$. There exists an outside earnings option $\bar{W} \geq 0$ for types when not being assigned as manager, i.e., with respect to all non-managerial tasks, labor is homogenous (see, e.g., Lucas (1978)). In the general equilibrium examples of section $4, \bar{W}$ is the wage rate for production workers. Firms take wages $w(h), h \in \mathcal{H}$, as given; there is a Walrasian auctioneer in the labor market, implementing a wage schedule which fulfills equilibrium conditions as defined 
in section 3.3 below (see Definition 2). Workers seek the highest wage.

Firms may (endogenously) differ in a single parameter $\alpha_{i}, i \in \mathcal{I}$, called quality of intangible assets. Intangible assets are created in the firms' head departments which consist of an exogenous mass ("size") $s$ of managerial workers, with $0<s \leq g(h)$ for all $h \in \mathcal{H}$. The quality index $\alpha_{i}$ is determined by the average managerial skill level in the head department of firm $i$, denoted by $\bar{h}_{i} \in H=\left[h^{0}, h^{K}\right]$. Formally, let $a: H \rightarrow \mathbb{R}_{+}$be a strictly monotonic increasing and twice continuously differentiable function, so that ${ }^{3}$

$$
\alpha_{i}=a\left(\bar{h}_{i}\right)
$$

There is a continuum of market locations ("markets"), indexed by $m$, which are represented as points in the unit interval $[0,1]$. In order to produce and sell products in a single market, firms have to incur set up costs, e.g., for opening up a plant or branch, introducing a marketing campaign at a location or costs associated with red tape. It is assumed that these costs only depend on the measure of markets in which a firm decides to operate, called market range. Formally, let $M_{i} \subseteq[0,1]$ be the set of markets in which firm $i \in \mathcal{I}$ is active and let $q_{i}$ be the Lebesgue measure of $M_{i}$. (It is assumed that $M_{i} \in \mathcal{M}$, where $\mathcal{M}$ is the $\sigma$-algebra of Borel sets for the unit interval.) Firm $i$ 's total set up costs are given by $Q\left(q_{i}\right)$, where $Q:[0,1] \rightarrow \mathbb{R}_{+}$is a monotonic increasing, convex and twice continuously differentiable function with $Q(0)=0$.

Let $\boldsymbol{\alpha}, \mathbf{M}$ and $\mathbf{q}$ denote mappings which assign to each firm $i$ a quality of intangible assets $\alpha_{i}$, a set of markets $M_{i}$ in which the firm is active and a corresponding market range $q_{i}$, respectively, $i \in \mathcal{I}$. The timing of events evolves according to the following stages, with decisions at each stage made simultaneously by firms.

- At stage 1 , each firm $i \in \mathcal{I}$ creates intangible assets by hiring managers from

\footnotetext{
${ }^{3}$ The size $s$ of head departments could be treated as choice variable of firms by replacing (1) by $\alpha_{i}=b\left(\bar{h}_{i}, s\right)$, as long as $b(\cdot)$ is not ever increasing in $s$ (holding $\bar{h}_{i}$ constant). (Such a limitation of size advantages can be justified by internal coordination problems which imply that a firm's head department has an optimal size.) This would not alter the main conclusions of this paper, but would considerably complicate the analysis. For simplicity, $s$ is exogenous here.
} 
the set $\mathcal{H}$, which determines $\boldsymbol{\alpha}$, according to equation (1). Wage costs for managers are sunk at later stages.

- At stage 2 , firms decide in which markets to be active, i.e., each firm $i \in \mathcal{I}$ chooses a set $M_{i} \in \mathcal{M}$, which determines $\mathbf{M}$ and $\mathbf{q}$, respectively.

- At stage 3, firms enter product market competition.

The analysis is not restricted to a particular type of imperfect competition model but generally applies to any form of imperfect product market competition in which intangible assets matter for the performance of firms. The role of intangible assets for the profits of firms at stage 3 is specified as follows. Denote profit realizations of firm $i$ from product market competition at stage 3 in market $m$ by $\pi_{i, m}$. The mapping $\mathbf{M}$, which assigns a set of markets $M_{i}$ to each firm $i \in \mathcal{I}$, determines for each $m \in[0,1]$ the set $\mathcal{N}_{m}:=\left\{i \in \mathcal{I} \mid m \in M_{i}\right\}$ of firms operating in market $m$. If firm $i$ does not enter market $m$, profits at stage 3 in this market are zero, i.e., $\pi_{i, m}=0$ if $i \notin \mathcal{N}_{m}$. If $i \in \mathcal{N}_{m}, \pi_{i, m}$ depends on the firm's strength $\alpha_{i}$ and on the competitive pressure exerted by its rivals.

A higher quality $\alpha_{i}$ raises $\pi_{i, m}$ in any market $m \in M_{i}$ (in which firm $i$ is active) similarly. This reflects the idea that intangible assets are geographical non-rival (as discussed in section 2.2). Competitive pressure in a market $m$ depends on the strengths of rivals $\alpha_{j}, j \in \mathcal{N}_{m}, j \neq i$. Thus, generally, profits at stage 3 in each market $m$ depend on $\boldsymbol{\alpha}$, i.e., on the quality levels of intangible assets developed at stage 1 , and on the mappings $\mathbf{M}$, q, resulting from the firms' decisions at stage 2 about which and how many markets to enter. The analysis focusses on (equilibrium) situations in which, given $\boldsymbol{\alpha}$, for any q, the profit-maximizing choices of market sets $M_{i}$ at stage 2 are such that each firm earns the same profit at stage 3 in any market it is active. More formally, let $z \equiv(\boldsymbol{\alpha}, \mathbf{q})$ denote the mapping which assigns a pair $\left(\alpha_{i}, q_{i}\right)$ to each firm $i$; then, one can write $\pi_{i, m}=\pi\left(\alpha_{i} \mid z\right)$ if $i \in \mathcal{N}_{m}$. As a consequence, the profit prospects $\pi_{i, m}$ faced by a firm when deciding about $\alpha_{i}$ and $q_{i}$ depend on $z$, not on specific conditions in single markets. ${ }^{4}$ Since single firms

\footnotetext{
${ }^{4}$ To see this, consider a situation in which competitive pressure differs across markets. Suppose
} 
have measure zero, competitive pressure under $\left(\boldsymbol{\alpha}^{\prime}, \mathbf{q}^{\prime}\right)$ is the same as under $(\boldsymbol{\alpha}, \mathbf{q})$ if $\alpha_{i}^{\prime}=\alpha_{i}$ and $q_{i}^{\prime}=q_{i}$ for almost all $i \in \mathcal{I}$. Competitive pressure under $\left(\boldsymbol{\alpha}^{\prime}, \mathbf{q}^{\prime}\right)$ is higher than under $(\boldsymbol{\alpha}, \mathbf{q})$ if $\alpha_{i}^{\prime} \geq \alpha_{i}$ and $q_{i}^{\prime} \geq q_{i}$ with at least one strict inequality holding for a positive mass of firms $i \in \mathcal{I}$. For instance, suppose there are two types of firms, indexed $k=0,1$, and denote the respective set of firms by $\mathcal{I}^{0}$ and $\mathcal{I}^{1}$, respectively; i.e., $\mathcal{I}=\mathcal{I}^{0} \cup \mathcal{I}^{1}$. Let $\left(\alpha_{i}, q_{i}\right)=\left(\alpha^{k}, q^{k}\right)$ for all $i \in \mathcal{I}^{k}, k=0,1$. Then, for all $i \in \mathcal{N}_{m}$ and for all $m \in[0,1], \pi_{i, m}=\pi\left(\alpha_{i} \mid z\right)$ is increasing in $\alpha_{i}$ and decreasing in $\alpha^{0}, \alpha^{1}, q^{0}$ and $q^{1}$. (See the examples in section 4.) The following assumption summarizes the properties of stage 3 equilibria required for the further analysis.

Assumption 1. For any $z=(\boldsymbol{\alpha}, \mathbf{q})$ there exists a real-valued function $\pi\left(\alpha_{i} \mid z\right)$, twice continuously differentiable in $\alpha_{i}$, so that $\pi_{i, m}=\pi\left(\alpha_{i} \mid z\right)$ if $i \in \mathcal{N}_{m}, m \in$ $[0,1]$, and $\pi$ satisfies the following properties: (i) $\frac{\partial \pi\left(\alpha_{i} \mid \cdot\right)}{\partial \alpha_{i}}>0$; (ii) for $z=(\boldsymbol{\alpha}, \mathbf{q})$, $z^{\prime}=\left(\boldsymbol{\alpha}^{\prime}, \mathbf{q}^{\prime}\right)$, we have $\pi\left(\alpha_{i} \mid z\right)=\pi\left(\alpha_{i} \mid z^{\prime}\right)$ if competitive pressure under $(\boldsymbol{\alpha}, \mathbf{q})$ and $\left(\boldsymbol{\alpha}^{\prime}, \mathbf{q}^{\prime}\right)$ is the same, and $\pi\left(\alpha_{i} \mid z\right)<\pi\left(\alpha_{i} \mid z^{\prime}\right)$ if competitive pressure under $(\boldsymbol{\alpha}, \mathbf{q})$ is higher than under $\left(\boldsymbol{\alpha}^{\prime}, \mathbf{q}^{\prime}\right)$.

Assumption 1 greatly simplifies the analysis, as the decision problem of each firm $i \in \mathcal{I}$ at stage 2 can be reduced to the choice of market ranges $q_{i}$ rather than the choice of the entire sets $M_{i}$.

Note that the firm's objective function at stage 2 is the sum of firm $i$ 's profits at stage 3 over all single markets in which it is active minus total entry costs $Q\left(q_{i}\right)$. As firms have a negligible impact, they correctly take $z$ as given at stage 2 . Thus, Assumption 1 implies that, given $z$, the optimal choice of range $q_{i}$ of a firm which has created a quality of intangible assets $\alpha_{i}$ at stage 1 reads

$$
\hat{q}\left(\alpha_{i} \mid z\right):=\arg \max _{0 \leq q_{i} \leq 1}\left\{q_{i} \pi\left(\alpha_{i} \mid z\right)-Q\left(q_{i}\right)\right\} .
$$

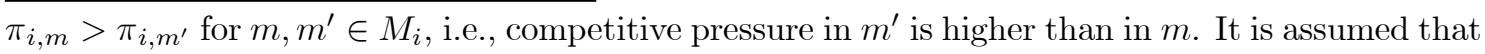
this cannot hold in an equilibrium because then other firms $j \notin \mathcal{N}_{m}$ should have been induced to enter market $m$ as well, or firm $i$ should have abstained to enter market $m^{\prime}$. Thus, in equilibrium, $\pi_{i, m}=\pi_{i, m^{\prime}}$ for all $m, m^{\prime} \in M_{i}$ and for all $i \in \mathcal{I}$. 


\subsection{Discussion of the Set Up}

Before beginning the equilibrium analysis, let me briefly discuss the set up of the model.

\subsubsection{Managerial Skills and Intangible Assets}

It is assumed that intangible assets have to be developed ex ante by managerial labor. For instance, managerial activities include the creation of analytical databases and intra-firm networks, which support the design of products, customer services and marketing strategies (e.g., Bresnahan (1999)). These tasks affect the (perceived) quality of goods. Moreover, managerial abilities affect the efficiency of the organizational structure of a firm (and, thus, productivity) by developing management techniques and firm-specific human capital (human resource management). Indeed, empirical evidence suggests that "managerial quality may be an important factor behind productivity heterogeneity" (Bartelsman and Doms (2000, p. 587)). As the creation of intangible assets relate to $R \& D$ and marketing activities, taking place prior to product market competition, the model borrows from the IO literature on investment games by treating corresponding outlays as endogenous sunk costs (e.g., Shaked and Sutton $(1982,1983)$, Sutton (1998)). In fact, the present model allows one to lead back endogenous sunk costs (i.e., managerial wages) to individual characteristics, accounting for individual heterogeneity and observing resource constraints.

\subsubsection{Geographical Non-rivalry of Intangible Assets}

According to the set up of section 2.1, the quality of intangible assets, $\alpha_{i}$, is firmspecific, rather than plant-specific. This reflects the public good nature of intangible assets from the perspective of a firm (therefore often called "common assets" in the literature). For instance, $\alpha_{i}$ corresponds to the perceived quality of the product(s) of firm $i$ in any market it chooses to be active. In this case, $\alpha_{i}$ can be interpreted as the consumers' valuation of firm $i$ 's product design(s) or trademark. According to the literature on the boundaries of (multi-plant) firms, intangible assets give rise to 
ownership advantages. ${ }^{5}$ In particular, this applies to multinational firms. In fact, firms in advertising-intensive industries are more likely to incur foreign direct investment (Martin (1991)). Moreover, firm-specific marketing advantages and trademarked goods induce firms to "globalize" (e.g., Markusen (1995), Wong (1995)). As another example, think about $\alpha_{i}$ as productivity of firm $i$. In fact, empirical evidence suggests that productivity in single plants of a firm is positively related to the productivity of the headquarter of this firm (Baily, Hulten and Campbell (1992)).

\subsubsection{Entry into single markets}

According to the model, entry into single markets is a prerequisite to participate in local product market competition, i.e., firms have to open a plant or branch in order to compete in a specific market. ${ }^{6}$ Moreover, it is implicitly assumed that costs of internal transactions are lower than those through market transactions (e.g., licensing $){ }^{7} Q(\cdot)$ constitutes plant-related sunk costs of firms, which have to be incurred in addition to the sunk costs for developing intangible assets. A strictly convex shape of $Q(\cdot)$ may be justified by logistic problems of firms to coordinate and govern single plants or branches. Microeconomic foundations of this assumption can be found in the literature on internal coordination problems (initiated by Coase (1937)). Reasons include diseconomies of scale in governing plants (Porter (1986))

\footnotetext{
${ }^{5}$ The notion of ownership advantages relates to the famous $O L I$ approach (e.g., Dunning (1981)). On the characteristics of multinational firms, see, e.g., Caves (1982) and Morck and Yeung (1992).

${ }^{6}$ For instance, suppose that transport costs are prohibitively high. Examples include service enterprises like hotel chains, restaurants, banks, airlines or car-rental companies. Moreover, think about firms which have own retail branches (for reasons related to marketing or trademarks) like Douglas, H\&M, IKEA, automobile manufactures, etc.

${ }^{7}$ According to the OLI framework, these two assumptions refer to locational and internalization advantages, respectively. Possible reasons for internalization advantages include agency problems (Holmström and Milgrom (1991, 1994)), asset specificity (Williamson (1979, 1985) or non-contractible investments (Grossman and Hart (1986), Hart and Moore (1990)). For a comprehensive outline of this literature, see, e.g., Holmström and Roberts (1998). Interestingly, these authors advise to study common assets as determinant for firm boundaries, rather than focussing on incentive problems only. This is the route taken in the present paper.
} 
and costs of bureaucracies (Williamson (1975)).

\section{Equilibrium Analysis}

This section solves the model by backward induction. The solution characterizes market ranges, profits, the wage structure, the assignment of ability types to firms and the measure of firms in an equilibrium.

\subsection{Product Market Competition (Stage 3)}

Product market competition at stage 3 takes place in each market $m \in[0,1]$ separately, with the set of firms $\mathcal{I}$, the qualities of intangible assets $\boldsymbol{\alpha}$ and market ranges $\mathbf{q}$ being already determined. According to Assumption 1, this leads to profit realizations $\pi\left(\alpha_{i} \mid z\right)$ of a firm with strength $\alpha_{i}$ in any market it is active, given the competitive pressure in the economy under $z=(\boldsymbol{\alpha}, \mathbf{q})$.

\subsection{Firms' Choice of Markets (Stage 2)}

Optimal behavior of firms $i \in \mathcal{I}$ at stage 2, after creation of intangible assets at stage 1 , is given by (2). This implies the following for an equilibrium at stage 2 .

Definition 1. (Equilibrium at stage 2). Given the set of firms $\mathcal{I}$ and the mapping $\boldsymbol{\alpha}$, in an equilibrium, we have $\tilde{z}=(\boldsymbol{\alpha}, \tilde{\mathbf{q}})$ with $\tilde{q}_{i}=\hat{q}\left(\alpha_{i} \mid \tilde{z}\right), i \in \mathcal{I}$.

As firms take $z$ as given when choosing market ranges, in equilibrium, the optimal choices of firms' market range, given by $\tilde{\mathbf{q}}$, must be consistent with the resulting competitive pressure under these optimal choices, i.e., $\tilde{z}=(\boldsymbol{\alpha}, \tilde{\mathbf{q}}){ }^{8}$ Equilibrium profits of a firm $i \in \mathcal{I}$ at stage 2 ("gross profits") then read

$$
\Pi\left(\alpha_{i} \mid \tilde{z}\right):=\tilde{q}_{i} \pi\left(\alpha_{i} \mid \tilde{z}\right)-Q\left(\tilde{q}_{i}\right) .
$$

\footnotetext{
${ }^{8}$ If there is a finite set of types of firms, as in the examples considered in section 4 below, the existence of an equilibrium at stage 2 can be established by applying standard fixed point theorems. Also note that there may be multiple equilibria, which, however, causes no problems in our analysis.
} 
Applying the Kuhn-Tucker theorem to the maximization problem (2), for all $i \in \mathcal{I}$, $\tilde{q}_{i}>0$ fulfills the condition

$$
\pi\left(\alpha_{i} \mid \tilde{z}\right) \geq Q^{\prime}\left(\tilde{q}_{i}\right)
$$

which is binding if $\tilde{q}_{i}<1 .^{9}$ Note that $\tilde{q}_{i}<1$ for some $i \in \mathcal{I}$ only if $Q\left(q_{i}\right)$ is strictly convex for at least some $q_{i} \in(0,1]$. To see this, suppose to the contrary that $Q(\cdot)$ would not be strictly convex somewhere. Then $\pi\left(\alpha_{i} \mid \tilde{z}\right) \geq Q^{\prime}(1)$ and $\tilde{q}_{i}=1$ would hold. As argued above, a strictly convex shape of set up costs $Q(\cdot)$ is a natural property which reflects diseconomies of scale in coordinating single branches or plants. The following result emerges. (All results are proven in appendix A.)

Proposition 1. (Market ranges and gross profits). For all $i \in \mathcal{I}$, (i) $\frac{\partial \tilde{q}_{i}}{\partial \alpha_{i}} \geq 0$, and (ii) $\frac{\partial \Pi\left(\alpha_{i} \mid \tilde{z}\right)}{\partial \alpha_{i}}>0$.

According to Proposition 1, firms with high-quality intangible assets are not only more profitable but, if anything, also have wider market ranges than firms with low-quality intangible assets. If $Q(\cdot)$ is strictly convex, then $\alpha_{i}>\alpha_{j}$ implies $\tilde{q}_{i}>\tilde{q}_{j}$ whenever $\tilde{q}_{j}<1$. Fig. 1 provides a graphical representation of Proposition 1 in this case. Making use of (3), differences in gross profits of firms $i$ and $j$ are given by the shaded area.

\section{$<$ Please insert Figure 1 about here $>$}

The next subsection shows that despite a completely symmetric situation of potential entrants in the economy, the quality of intangible assets (and, thus, profits as well as, possibly, market ranges) may indeed differ among firms in equilibrium, as an implication of the endogenous sorting of managers into head departments. For both the intuition of this central result and its implication for the size distribution of firms (discussed in section 5), the following auxiliary result will prove helpful.

\footnotetext{
${ }^{9}$ Clearly, $\pi\left(\alpha_{i} \mid \tilde{z}\right)>Q^{\prime}(0)$ and thus $\tilde{q}_{i}>0$ in any equilibrium, because otherwise a firm would not enter the economy in the first place. Also note that $\Pi\left(\alpha_{i} \mid \tilde{z}\right)>0$ for all $i \in \mathcal{I}$, according to (3), (4), $\pi\left(\alpha_{i} \mid \tilde{z}\right)>Q^{\prime}(0)$, the convexity of $Q(\cdot)$ and $Q(0)=0$.
} 
Lemma 1. (Convexity properties). Suppose $\frac{\partial^{2} \pi\left(\alpha_{i} \mid \cdot\right)}{\partial \alpha_{i}^{2}}>0$. Then $\frac{\partial^{2} \Pi\left(\alpha_{i} \mid \cdot\right)}{\partial \alpha_{i}^{2}}>0$ and, if $\tilde{q}_{i}<1$ and $Q^{\prime \prime \prime}\left(\tilde{q}_{i}\right) \leq 0$, also $\frac{\partial^{2} \tilde{q}_{i}}{\partial \alpha_{i}^{2}}>0$.

As will be seen below, strict convexity of reduced-form profits at stage $3, \pi\left(\alpha_{i} \mid \cdot\right)$, in $\alpha_{i}$ gives rise to a complete segregation of firms by managerial skill.

\subsection{Assignment of Managerial Skills (Stage 1)}

The firms' decision problem at stage 1 is to choose the quality of intangible assets $\alpha_{i}$ by hiring managers. First, define a class of "assignment functions"

$$
\tilde{G}:=\left\{\tilde{g}: \mathcal{H} \rightarrow[0, s] \mid \tilde{g}(h) \leq g(h) \text { for all } h \in \mathcal{H} \text { and } \sum_{h \in \mathcal{H}} \tilde{g}(h)=s\right\} .
$$

$\tilde{G}$ describes the feasible hiring policies of a firm. At stage 1, each firm $i \in \mathcal{I}$ chooses an assignment function $\tilde{g}_{i} \in \tilde{G}$. Depending on this hiring policy, the average managerial skill level in firm $i$ is given by $\bar{h}_{i}=\frac{1}{s} \sum_{h \in \mathcal{H}} h \tilde{g}_{i}(h)$. As $\alpha_{i}=a\left(\bar{h}_{i}\right)$, the set of functions $\tilde{g}_{i} \in \tilde{G}, i \in \mathcal{I}$, determines the mapping $\boldsymbol{\alpha}$. It is helpful to redefine profits at stage 2 as function of firms' average managerial skill level $\bar{h}_{i}$, i.e.,

$$
f\left(\bar{h}_{i} \mid \cdot\right):=\Pi\left(a\left(\bar{h}_{i}\right) \mid \cdot\right)
$$

We are now ready to set up conditions for an equilibrium at stage 1.

Definition 2. (Equilibrium at stage 1). An equilibrium set of assignment functions $\tilde{g}_{i}^{*} \in \tilde{G}, i \in \mathcal{I}$, together with a mapping $w$ from $\mathcal{H}$ to $\mathbb{R}_{+}$(wage schedule), fulfill the following conditions:

(a) Net profits are zero, i.e., for all $i \in \mathcal{I}$,

$$
f\left(\bar{h}_{i}^{*} \mid z^{*}\right)=\sum_{h \in \mathcal{H}} w(h) \tilde{g}_{i}^{*}(h),
$$

where $\bar{h}_{i}^{*}=\frac{1}{s} \sum_{h \in \mathcal{H}} h \tilde{g}_{i}^{*}(h)$ and $z^{*}=\left(\boldsymbol{\alpha}^{*}, \mathbf{q}^{*}\right)$, with $\alpha_{i}^{*}=a\left(\bar{h}_{i}^{*}\right)$ and $q_{i}^{*}=\hat{q}\left(\alpha_{i}^{*} \mid z^{*}\right)$, $i \in \mathcal{I}$.

(b) Given $z^{*}$, no profitable deviation exists, i.e., for all $\tilde{g}_{i}^{\prime} \in \tilde{G}$ and for all $i \in \mathcal{I}$,

$$
f\left(\bar{h}_{i}^{\prime} \mid z^{*}\right) \leq \sum_{h \in \mathcal{H}} w(h) \tilde{g}_{i}^{\prime}(h)
$$


where $\bar{h}_{i}^{\prime}=\frac{1}{s} \sum_{h \in \mathcal{H}} h \tilde{g}_{i}^{\prime}(h)$.

(c) For all $h \in \mathcal{H}, w(h) \geq \bar{W}$ and the following holds: if $w(h)>\bar{W}$, then $\int_{i \in \mathcal{I}} \tilde{g}_{i}^{*}(h) d i=g(h) ;$ if $\int_{i \in \mathcal{I}} \tilde{g}_{i}^{*}(h) d i<g(h)$, then $w(h)=\bar{W}$.

Condition (a) of Definition 2 means that the total wage bill for managers employed in the head department of a firm (i.e., the endogenous sunk cost for the creation of intangible assets) is equal to its gross profit, i.e., net profits of all firms are zero in equilibrium. In view of free entry of firms into the economy and the competition of firms for managerial skills in a perfect labor market, this is a consistent requirement. With symmetry of potential entrants ex ante, the only possibility for a firm to become more profitable (in terms of gross profits at stage 2) than other firms is to attract higher-skilled managers on average. Higher gross profits of a firm just transmit into a higher average wage per manager of a firm. Also note that, in any equilibrium, firms must correctly foresee the competitive pressure $z^{*}$, which results from optimizing behavior of firms at stages 1 and 2 (recall Definition 1), as well as from product market competition at stage 3 . Condition (b) reflects that, at stage 1, each firm maximizes profits taking both competitive pressure $z^{*}$ and the wage schedule $w(h), h \in \mathcal{H}$, as given. To see this, note that for any given wage schedule $w(h), h \in \mathcal{H}$, no firm $i$ wants to deviate from $\tilde{g}_{i}^{*} \in \tilde{G}$ (which leads to average skill $\left.\bar{h}_{i}^{*}\right)$ iff

$$
f\left(\bar{h}_{i}^{*} \mid z^{*}\right)-\sum_{h \in \mathcal{H}} w(h) \tilde{g}_{i}^{*}(h) \geq f\left(\bar{h}_{i}^{\prime} \mid z^{*}\right)-\sum_{h \in \mathcal{H}} w(h) \tilde{g}_{i}^{\prime}(h)
$$

for all alternative assignment functions $\tilde{g}_{i}^{\prime} \in \tilde{G}$ (leading to $\bar{h}_{i}^{\prime}$ ). Inequality (8) then directly follows from (9) by using the zero-profit condition (a). According to condition (c), all types $h \in \mathcal{H}$ from the potential pool of managers must at least receive the outside option $\bar{W}$ (i.e., the wage rate for non-managerial labor). This implies $f\left(\bar{h}_{i}^{*} \mid z^{*}\right) \geq s \bar{W}$ for all $i \in \mathcal{I}$, i.e., sunk costs are bounded from below by $s \bar{W}$. As argued in section 3.4, this determines the equilibrium measure of firms $I^{*}$ under free-entry. Condition (c) also says that the market for managerial skills must clear for any type $h$ unless workers are paid their outside option. To see this, suppose $w(h)>\bar{W}$ and $\int_{i \in \mathcal{I}} \tilde{g}_{i}^{*}(h) d i<g(h)$. This means that there is excess supply for man- 
agerial positions as workers seek the highest wage. However, this is inconsistent with a Walrasian equilibrium in the labor market. In contrast, if $w(h)=\bar{W}$ for some type $h$, then this type is indifferent whether or not to be assigned as manager.

Remark 1. Definition 2 extends the equilibrium definition in Saint-Paul (2001) to analyze the assignment of managerial skills to head departments of firms in an imperfect competition, multi-market context in which managers develop intangible assets. In contrast, Saint-Paul examines the relationship between technological change and wage inequality by studying the assignment of production workers to firms under perfect competition. Formally, however, the basic model of Saint-Paul is a special case of the present framework in which $\bar{W}=0$ (i.e., there is no outside wage option) and $f\left(\bar{h}_{i} \mid \cdot\right)=\pi\left(a\left(\bar{h}_{i}\right) \mid \cdot\right) \equiv a\left(\bar{h}_{i}\right)$ for all $i \in \mathcal{I}$. That is, in his model, $a\left(\bar{h}_{i}\right)$ is firm $i$ 's output of a homogenous (numeraire) good in a single market when employing $s$ workers with average skill level $\bar{h}_{i}$. (There are no set up costs for market entry.) Using this, conditions (a) and (b) of Definition 2 hold in an analogous way (replacing $f\left(\bar{h}_{i}^{*} \mid z^{*}\right)$ by $a\left(\bar{h}_{i}^{*}\right)$ ), although wage costs do not have the interpretation of sunk investments in the set up of Saint-Paul. Moreover, in his model $w(h)>0(=\bar{W})$ for all $h$; i.e., there is full employment of all types, according to equilibrium condition (c). Correspondingly, the equilibrium measure of firms is given by $I^{*}=1 / s$ in this case. ${ }^{10}$

We are now ready to derive the equilibrium wage structure. Define the sets $S_{i}:=\left\{h \in \mathcal{H}: \tilde{g}_{i}^{*}(h)>0\right\}$ which contain managerial skill levels (of a total mass $s$ of types) hired in equilibrium by $i \in \mathcal{I}$. Let $\mathbf{S}$ be a mapping which assigns a set $S_{i}$ to each firm $i$, called an equilibrium configuration of manager assignments. Also define $\mathcal{S}:=\cup_{i \in \mathcal{I}} S_{i}$, i.e., $\mathcal{S} \subseteq \mathcal{H}$ is the subset of managerial skill levels assigned to head departments in equilibrium. At stage 1 , each firm $i \in \mathcal{I}$ chooses an assignment

\footnotetext{
${ }^{10}$ As shown in section 3.4 and illustrated in appendix, if $\bar{W}>0$, by contrast, the equilibrium measure of firms $I^{*}$ depends on all exogenous factors, i.e., besides on size $s$ of head departments, on the product demand structure, the nature of product market competition, technologies, and the distribution of managerial skills.
} 
function $\tilde{g}_{i} \in \tilde{G}$ by maximizing net profits $f\left(\bar{h}_{i} \mid z^{*}\right)-\sum_{h \in \mathcal{H}} \tilde{g}_{i}(h) w(h)$, taking $z^{*}$ and the wage schedule $w(h)$ for each type $h \in \mathcal{H}$ as given. Observing equilibrium conditions (a)-(c) of Definition 2, we can characterize the equilibrium wage schedule as follows.

Proposition 2. (Wage schedule). In equilibrium,

(i)

$$
w(h) \geq \frac{f\left(\bar{h}_{i}^{*} \mid z^{*}\right)}{s}+\frac{\partial f\left(\bar{h}_{i}^{*} \mid z^{*}\right)}{\partial \bar{h}_{i}} \frac{h-\bar{h}_{i}^{*}}{s}
$$

for all $h \in \mathcal{S}$, with equality if $h \in S_{i}, i \in \mathcal{I}$;

(ii) there exists $h^{\min } \in \mathcal{H}$ such that $\mathcal{S}=\left\{h^{\min }, \ldots, h^{K}\right\}$;

(iii) $w(h)>\bar{W}$ for all $h>h^{\mathrm{min}}$;

(iv) finally, $w\left(\bar{h}_{i}^{*}\right)=f\left(\bar{h}_{i}^{*} \mid z^{*}\right) / s, i \in \mathcal{I}$.

According to part (i), within the head department of a firm $i \in \mathcal{I}$ (i.e., for all $h \in S_{i}$ ), the equilibrium wage schedule is colinear. This is a direct implication of the assumption that a firm i's quality of intangible assets $\alpha_{i}$ depends on the average managerial skill level $\bar{h}_{i}$ it hires. The right-hand side of (10) gives the marginal benefit from hiring a manager of type $h$ for a firm with average skill level $\bar{h}_{i}^{*}$ under the zero-profit condition (7). Thus, in equilibrium, type $h$ is not employed in such a firm if $w(h)$ exceeds this marginal benefit. (Compare to Saint-Paul (2001).) Part (ii) states that there is an endogenous cut-off ability level $h^{\min }$ (i.e., a minimum skill) for managers. According to part (iii), workers whose managerial skills exceed those of the least skilled type $h^{\text {min }}$ assigned as manager have strictly higher earnings than their outside opportunity $\bar{W}$ in equilibrium (whereas $w\left(h^{\mathrm{min}}\right)=\bar{W}$ if some workers of type $h^{\mathrm{min}}$ are not assigned as manager, according to part (c) of Definition 2). Finally, according to part (iv), any worker of type $\bar{h}_{i}^{*}$ must obtain a wage rate equal to the average wage (or average gross profit, respectively) per manager in firm $i$ (whether or not type $\bar{h}_{i}^{*}$ is actually employed in firm $i$ ).

Armed with the results of Proposition 2, the equilibrium assignment of managers is analyzed next. First, the following definition is made.

Definition 3. (Polar cases). An equilibrium configuration of manager assignments $\mathbf{S}$ is called hypersegregated if $S_{i}=\left\{\bar{h}_{i}^{*}\right\}$ for all $i \in \mathcal{I}$, i.e., if all firms hire a 
single type of manager only. $\mathbf{S}$ is called symmetric if $\bar{h}_{i}^{*}=\bar{h}^{*}$ for all $i \in \mathcal{I}$, i.e., if the average managerial skill level is the same in each firm.

The following proposition shows under which properties these polar cases occur in equilibrium, which also plays a crucial role in the examples of section 4 .

Proposition 3. (Properties of stage 2 profits and polar cases). In any equilibrium, the configuration of manager assignments $\mathbf{S}$ is hypersegregated (symmetric) if profit functions at stage $2, f\left(\bar{h}_{i} \mid z\right)$, evaluated at equilibrium values $\bar{h}_{i}^{*}$ and $z^{*}$, $i \in \mathcal{I}$, are strictly convex (strictly concave) in $\bar{h}_{i}$.

Intuitively, Proposition 3 can be understood by the properties of the managerial wage schedule, derived in Proposition 2. First, suppose that $f(h \mid \cdot) / s$ is strictly convex in $h$, as depicted by the solid line in Fig. 2. If firm $i$ employs more than one type of manager, then, in any equilibrium, the wage differential $w(\hat{h})-w(\tilde{h})$ between two types $\hat{h}, \tilde{h} \in S_{i}$ is proportional to the skill differential $\hat{h}-\tilde{h}$. The average gross profit per manager of this firm, with average managerial skill $\bar{h}_{i}$, is given by $f\left(\bar{h}_{i} \mid \cdot\right) / s$. Thus, wages $w(\hat{h})$ and $w(\tilde{h})$ lie on the tangent (indicated by the dotted line) of $f(h \mid \cdot) / s$ at $\bar{h}_{i}$ (point A). Now suppose firm $i$ would raise its average managerial skill level from $\bar{h}_{i}$ to $\bar{h}_{i}^{\prime}$ by replacing some managers of type $\tilde{h}$ by some of type $\hat{h}>\tilde{h}$. This leads to additional average wage cost per manager of $\overline{\mathrm{CD}}$ and to additional average gross profits per manager of $\overline{\mathrm{BD}}$. $\mathrm{As} \overline{\mathrm{BD}}>\overline{\mathrm{CD}}$, this means that, whenever firm $i$ employs more than one type of manager under strict convexity of $f(h \mid \cdot)$ in $h$, a profitable deviation exists. However, this violates equilibrium condition (b) of Definition 2. Consequently, $\mathbf{S}$ is hypersegregated.

\section{$<$ Please insert Figure 2 about here $>$}

For instance, if $f\left(\bar{h}_{i} \mid \cdot\right)=a\left(\bar{h}_{i}\right)$ as in Saint-Paul (2001) (see Remark 1), then $a^{\prime \prime}(\cdot)>0$ ("increasing marginal returns to skill") implies complete segregation of skills in sorting equilibrium. As argued by Saint-Paul, this corresponds to the special case of an "O-ring" production function, analyzed by Kremer (1993), in which workers exert spillovers on each other at all skill levels. In the present context, if 
the profit function at stage $3, \pi\left(\alpha_{i} \mid \cdot\right)$, is strictly convex in $\alpha_{i}$, and, for instance, $a\left(\bar{h}_{i}\right)=\bar{h}_{i}$, then also $f\left(\bar{h}_{i} \mid z\right)$ is strictly convex in $\bar{h}_{i}$, according to Lemma 1 . As a result, according to Proposition 3, firms are completely segregated by managerial skill in equilibrium, even without intra-firm spillovers. In turn, firms differ in gross profits and, possibly, in market ranges, according to Proposition 1. As will be seen in section 4 , strict convexity of profit functions in perceived product quality or the level of productivity, respectively, is indeed a natural property in standard imperfect competition models. Generally, and in contrast to the previous literature on job assignment, product market characteristics determine the equilibrium outcome of the sorting process. Assuming increasing marginal returns to skill in the technology to create intangible assets would just be an additional force towards asymmetric equilibria in the present analysis.

Second, strict concavity of $f\left(\bar{h}_{i} \mid z^{*}\right)$ in $\bar{h}_{i}$ implies that all firms must have the same average managerial skill level in equilibrium. This directly follows from the fact (established in the proof of Proposition 3) that the wage schedule for managers in a more profitable firm cannot be less steep than in a less profitable firm.

The next proposition generally characterizes the equilibrium configuration of manager assignments which results from the endogenous sorting of managers into head departments of firms.

Proposition 4. (General sorting property). The equilibrium configuration of manager assignments $\mathbf{S}$ can be characterized by a partition of $\mathcal{S}=\left\{h^{\min }, \ldots, h^{K}\right\}$ into adjacent subsets $\mathcal{S}_{\varphi}$, indexed $\varphi \in \Phi$, which fulfill the following. There exist $\mathcal{I}_{\varphi}:=\left\{i \in \mathcal{I}: S_{i} \subseteq \mathcal{S}_{\varphi}\right\}$ such that $\underset{i \in \mathcal{I}_{\varphi}}{\cup} S_{i}=\mathcal{S}_{\varphi}$ for all $\varphi \in \Phi$.

Proposition 4 says that, for instance, in an asymmetric equilibrium (i.e., whenever $\bar{h}_{i} \neq \bar{h}_{j}$ for some $i, j \in \mathcal{I}$ ), if firm $i$ hires managers from some subset $S_{i}=$ $\left\{h^{k}, \ldots, h^{l}\right\} \subset \mathcal{H}$ and $\bar{h}_{i}^{*}>(<) \bar{h}_{j}^{*}$, then all managers in firm $j$ have skills $h \leq h^{l}$ $\left(h \geq h^{k}\right)$. This also implies that the wage schedule within two firms which hire managers from the same subset $\mathcal{S}_{\varphi} \subseteq \mathcal{H}$ is the same in both firms, according to part (i) of Proposition 2. 


\subsection{Entry and the Number of Firms}

This subsection shows how the equilibrium measure of firms, denoted $I^{*}$, can be determined by observing the equilibrium conditions in Definition 2 (in particular, condition (c)) together with Proposition 2.

If $\bar{W}=0$, then entry is restricted by the resource constraint for managerial types, i.e., $I^{*}=1 / s$ and $h^{\min }=h^{0}$. Generally, allowing for $\bar{W}>0$, the equilibrium measure of firms is given by

$$
I^{*}=\frac{1}{s}\left(\hat{g}\left(h^{\min }\right)+\sum_{h \in \mathcal{S} \backslash\left\{h^{\min }\right\}} g(h)\right),
$$

where $\hat{g}\left(h^{\text {min }}\right):=\int_{i \in \mathcal{I}} \tilde{g}_{i}^{*}\left(h^{\text {min }}\right) d i$ is the equilibrium mass of types $h^{\text {min }}$ assigned as manager. Note that $w\left(h^{\min }\right)>\bar{W}$ implies $\hat{g}\left(h^{\min }\right)=g\left(h^{\min }\right)$, whereas $\hat{g}\left(h^{\min }\right)<$ $g\left(h^{\text {min }}\right)$ can hold only if $w\left(h^{\text {min }}\right)=\bar{W}$, according to equilibrium condition (c) of Definition 2. In the following, the equilibrium measure of firms $I^{*}$ is characterized for the two polar cases of Definition 3.

First, suppose the equilibrium configuration of manager assignments $\mathbf{S}$ is hypersegregated. Thus, because $\int_{i \in \mathcal{I}} \tilde{g}_{i}^{*}(h) d i=g(h)$ for all $h \in \mathcal{S} \backslash\left\{h^{\mathrm{min}}\right\}$ and head departments are of size $s \in(0, g(h)]$, there are $g\left(h^{K}\right) / s$ firms with single type $h^{K}$, $g\left(h^{K-1}\right) / s$ firms with single type $h^{K-1}$ and so on; the mass of firms with type $h^{\text {min }}$ is given by $\hat{g}\left(h^{\text {min }}\right) / s$. Moreover, we have the mapping $\boldsymbol{\alpha}^{*}: \mathcal{I} \rightarrow\left\{\alpha^{\min }, \ldots, \alpha^{K}\right\}$, where $\alpha^{\min }=a\left(h^{\min }\right), \ldots, \alpha^{K}=a\left(h^{K}\right)$. According to Proposition 2, if $\mathbf{S}$ is hypersegregated, $\hat{g}\left(h^{\min }\right)$ and $w\left(h^{\min }\right)$ (and thus $\left.h^{\text {min }}\right)$ must fulfill

$$
f\left(h^{\min } \mid z^{*}\right)=s w\left(h^{\min }\right)
$$

with $w\left(h^{\min }\right)=\bar{W}$ if $\hat{g}\left(h^{\min }\right)<g\left(h^{\min }\right)$ or $\hat{g}\left(h^{\min }\right)=g\left(h^{\min }\right), z^{*}=\left(\boldsymbol{\alpha}^{*}, \mathbf{q}^{*}\right)$. Together with $(11)$, these relations simultaneously determine $\hat{g}\left(h^{\min }\right), w\left(h^{\min }\right)$ and $I^{*}$ in an equilibrium with complete segregation by managerial skill.

Second, suppose the equilibrium configuration of manager assignments $\mathbf{S}$ is symmetric. That is, all firms have the average quality of types assigned as manager, i.e., 
$\bar{h}_{i}^{*}=\bar{h}^{*}$ for all $i \in \mathcal{I}$ with

$$
\begin{aligned}
\bar{h}^{*} & =\frac{1}{s I^{*}}\left(h^{\min } \hat{g}\left(h^{\min }\right)+\sum_{h \in \mathcal{S} \backslash\left\{h^{\text {min }}\right\}} h g(h)\right) \\
& =\frac{h^{\min } \hat{g}\left(h^{\min }\right)+\sum_{h \in \mathcal{S} \backslash\left\{h^{\text {min }}\right\}} h g(h)}{\hat{g}\left(h^{\text {min }}\right)+\sum_{h \in \mathcal{S} \backslash\left\{h^{\text {min }}\right\}} g(h)},
\end{aligned}
$$

where (11) has been used for the latter equation. If $\mathbf{S}$ is symmetric, then $\hat{g}\left(h^{\mathrm{min}}\right)$ and $w\left(h^{\mathrm{min}}\right)$ (and thus $\left.h^{\mathrm{min}}\right)$ fulfill

$$
s w\left(h^{\min }\right)=f\left(\bar{h}^{*} \mid z^{*}\right)+\frac{\partial f\left(\bar{h}^{*} \mid z^{*}\right)}{\partial \bar{h}_{i}}\left(h^{\min }-\bar{h}^{*}\right),
$$

with $w\left(h^{\min }\right)=\bar{W}$ if $\hat{g}\left(h^{\min }\right)<g\left(h^{\min }\right)$ or $\hat{g}\left(h^{\min }\right)=g\left(h^{\min }\right)$, and $\bar{h}^{*}$ as in equation (13).

\section{Examples}

This section characterizes the equilibrium in specific models of imperfect (i.e., monopolistic) product market competition among firms at stage 3. (Existence of equilibrium is discussed in appendix.) It is illustrated that the coexistence of different types of firms (with different gross profits and market ranges, respectively), which stems from an asymmetric (e.g., hypersegregated) equilibrium configuration of manager assignments, is indeed likely to emerge in standard models. (Note that gross profits and market ranges are identical among firms if and only if the configuration of manager assignments is symmetric.)

Two monopolistic competition models are considered. The first specification considers a version of the CES-utility model by Dixit and Stiglitz (1977), widely used in macroeconomic theory, which allows for asymmetric firms. The second specification assumes linear demand schedules (i.e., quadratic utility), along the lines of Ottaviano and Thisse (1999), also extended for asymmetric firms. 


\subsection{CES-Utility}

Let markets be symmetric in the sense that both population size and the skill structure is identical in each market. Consumers and workers are immobile, i.e., are tied to their market location. In particular, managers work wherever they are located. That is, the firms' head departments are decentrally organized, i.e., cannot be attributed to a specific market location. (These additional assumptions can be abandoned in the linear-demand model of section 4.2 in which product demand does not depend on aggregate income at a market location.) Each firm $i$ produces one variety of a differentiated good at each of its plants. Labor is the only input in production. Firms have a constant-returns-to-scale technology, possibly differing in productivity $\beta_{i}$ of non-managerial labor. Normalizing the wage rate for production labor to unity (i.e., $\bar{W}=1$ ), marginal production cost are given by $1 / \beta_{i}$.

The utility function of the representative consumer in a market $m$ is defined over a set $\mathcal{N}_{m}$ of goods supplied in this market, and is given by the CES-index

$$
U=\left(\int_{i \in \mathcal{N}_{m}}\left(\gamma_{i} x_{i, m}\right)^{\frac{\sigma}{\sigma-1}} d i\right)^{\frac{\sigma-1}{\sigma}}
$$

$\sigma>1$, where $x_{i, m}$ is the quantity of variety $i$ in market $m$ and $\gamma_{i}$ indicates the perceived quality of goods in any market in which firm $i$ is active. Denoting consumption expenditure in market $m$ by $E_{m}$ and the price for variety $i$ in $m$ by $p_{i, m}$, (15) implies the following demand functions:

$$
x_{i, m}=\left(\gamma_{i}\right)^{\sigma-1} \frac{E_{m}}{P_{m}}\left(\frac{p_{i, m}}{P_{m}}\right)^{-\sigma},
$$

$i \in \mathcal{N}_{m}$, where $P_{m}:=\left(\int_{i \in \mathcal{N}_{m}}\left(p_{i, m} / \gamma_{i}\right)^{1-\sigma} d i\right)^{\frac{1}{1-\sigma}}$ is the price index in market $m$. $P_{m}$ is defined in a way such that indirect utility equals "real" expenditure $E_{m} / P_{m}$. Firms take both aggregate expenditure $E_{m}$ and the price index $P_{m}$ as given in setting prices.

As shown in appendix $\mathrm{B}$, the equilibrium profit of firm $i \in \mathcal{N}_{m}$ from monopolistic product market competition at stage 3 takes the simple form

$$
\pi_{i, m}=\frac{\left(\alpha_{i}\right)^{\sigma-1}}{\Xi_{m}} \frac{L_{m}}{\sigma-1}
$$


where $\alpha_{i}:=\beta_{i} \gamma_{i}$ and $\Xi_{m}:=\int_{i \in \mathcal{N}_{m}}\left(\alpha_{i}\right)^{\sigma-1} d i ; L_{m}$ denotes the aggregate amount of non-managerial labor, devoted to the production of goods, in market $m$. Note that, consistent with the general structure of the model, the quality of intangible assets of firm $i$ can be summarized by a single parameter $\alpha_{i}$. Managers affect a firm's profits by determining either productivity $\beta_{i}$ (e.g., by creating an organizational structure) or perceived quality $\gamma_{i}$ (e.g., by designing products).

How can one conclude from (17) how the configuration of manager assignments is characterized in equilibrium? Let $N_{m}$ denote the measure of the set $\mathcal{N}_{m}$, i.e., the "number" of establishments in market $m \in[0,1]$. As markets are symmetric ex ante, we focus on equilibria in which the composition of firm types is the same in each market. Thus, in equilibrium, $L_{m}^{*}=L^{*}, \Xi_{m}^{*}=\Xi^{*}$ and $N_{m}^{*}=N^{*}$ for all $m \in[0,1]$, where

$$
N^{*}=\int_{m \in[0,1]} N_{m}^{*} d m \equiv \int_{i \in \mathcal{I}} q_{i}^{*} d i .
$$

For simplicity, let there be just two types of managerial skills in the economy, i.e., $\mathcal{H}=\left\{h^{0}, h^{1}\right\}$, with $0<h^{0}<h^{1}<\infty$. $^{11}$

Now suppose that firms are completely segregated by managerial skill. It is now examined under which conditions this is consistent with an equilibrium. In order to avoid the discussion of many case distinctions, we focus on an equilibrium in which also (some) workers with skill $h^{0}$ are assigned as manager. That is, we look for an equilibrium with two types of firms, one that hires managers from type $h^{0}$ only and one that hires type $h^{1}$ only. Denote the respective sets of firms by $\mathcal{I}^{0}$ and $\mathcal{I}^{1}$, with equilibrium measures $I^{0}$ and $I^{1}=I^{*}-I^{0}$, respectively. Equilibrium mappings $\boldsymbol{\alpha}^{*}$ and $\mathbf{q}^{*}$ are such that $\alpha_{i}^{*}=a\left(h^{k}\right) \equiv \alpha^{k}$ and $q_{i}^{*} \equiv q^{k}$ for all $i \in \mathcal{I}^{k}, k=0,1$, respectively. With a share $r \equiv I^{0} / I^{*}$ of firms with skill $h^{0}$ being active in each market $m$, the equilibrium number of firms in each market reads

$$
N^{*}=I^{*}\left(r q^{0}+(1-r) q^{1}\right),
$$

\footnotetext{
${ }^{11}$ Extension to the general case of $K+1$ types is straightforward.
} 
according to (18). Moreover, as $\Xi^{*}=\int_{0}^{N^{*}}\left(\alpha_{i}\right)^{\sigma-1} d i$, we have

$$
\begin{aligned}
\Xi^{*} & =N^{*}\left[r\left(\alpha^{0}\right)^{\sigma-1}+(1-r)\left(\alpha^{1}\right)^{\sigma-1}\right] \\
& =I^{*}\left(r q^{0}+(1-r) q^{1}\right)\left[r\left(\alpha^{0}\right)^{\sigma-1}+(1-r)\left(\alpha^{1}\right)^{\sigma-1}\right],
\end{aligned}
$$

where the latter equation is implied by (19). Finally, with a population size of unity in the economy, the equilibrium amount of production workers is given by $L^{*}=1-s I^{*}$ (full employment). Hence, (17) can be rewritten as

$$
\pi_{i, m}=\pi\left(\alpha_{i} \mid z^{*}\right)=\frac{\left(\alpha_{i}\right)^{\sigma-1}}{I^{*}\left(r q^{0}+(1-r) q^{1}\right)\left[r\left(\alpha^{0}\right)^{\sigma-1}+(1-r)\left(\alpha^{1}\right)^{\sigma-1}\right]} \frac{1-s I^{*}}{\sigma-1}
$$

for all $i \in \mathcal{N}_{m}$ under hypersegregation with two firm types (recall $z^{*}=\left(\boldsymbol{\alpha}^{*}, \mathbf{q}^{*}\right)$ ). Given $z^{*}, \pi\left(\alpha_{i} \mid z^{*}\right)$ increases in $\alpha_{i}$, in line with part (i) of Assumption 1. Also part (ii) of Assumption 1 is fulfilled as single firms have measure zero and $\pi\left(\alpha_{i} \mid z^{*}\right)$ decreases in $\alpha^{k}$ and $q^{k}, k=0,1$ (i.e., profits at stage 3 decrease if competitive pressure, which is determined by the correctly foreseen equilibrium values $\Xi^{*}$ and $I^{*}$, increases). Note that $\pi\left(\alpha_{i} \mid z^{*}\right)$ is strictly convex in $\alpha_{i}$ if $\sigma>2$. Consequently, applying Lemma 1 and recalling $f\left(\bar{h}_{i} \mid \cdot\right)=\Pi\left(a\left(\bar{h}_{i}\right) \mid \cdot\right)$, the following result emerges from (21).

Proposition 5. (Monopolistic competition with CES-utility). Under utility specification (15) with $\alpha_{i}=\beta_{i} \gamma_{i}$, if $\sigma$ is sufficiently high, then the equilibrium configuration of manager assignments $\mathbf{S}$ is hypersegregated.

Proposition 5 provides an interesting intuition for the emergence of segregation of firms by managerial skill under monopolistic competition à la Dixit and Stiglitz (1977). A high price elasticity of demand $\sigma$ (i.e., products are good substitutes such that monopoly power of firms is low, all other things equal) is associated with a high intensity of product market competition. Consequently, a given difference in the quality of intangible assets among firms becomes increasingly magnified into differences in profits at stage 3 (i.e., $\pi\left(\alpha_{i} \mid z^{*}\right)$ is strictly convex in $\alpha_{i}$.) This has a symmetry-breaking feedback effect on the job assignment of managers, resulting from labor market competition. For instance, if $a(\cdot)$ is linear, then $\sigma>2$ is sufficient 
for a hypersegregated configuration of manager assignments. Interestingly, starting from a symmetric equilibrium (which may exist for a low value of $\sigma$ ), the model is capable to generate the following comparative-static result. If the price elasticity of demand $\sigma$ increases such that the equilibrium becomes asymmetric, some firms actually increase their market power by attracting better managers, while other firms see their (gross) profits shrink. Thus, somewhat paradoxically, a higher intensity of product market competition may give rise to the emergence of "global players" in the first place, characterized by (relatively) high gross profits and wide market ranges.

So far, existence of equilibrium has been supposed. In appendix C, the preceding example is used to illustrate how to prove existence of an equilibrium for the two polar cases of a hypersegregated and a symmetric equilibrium configuration of manager assignments, respectively.

\subsection{Quadratic Utility}

Next, consider monopolistic competition in each market $m$ under quasi-linear preferences, adopted from Ottaviano and Thisse (1999), which are represented by the following utility function over a set $\mathcal{N}_{m}$ of " $x$-goods" and a numeraire commodity:

$$
U=\int_{i \in \mathcal{N}_{m}} A_{i} x_{i, m} d i-\frac{1}{2} \beta \int_{i \in \mathcal{N}_{m}}\left(x_{i, m}\right)^{2} d i-\gamma \int_{i \in \mathcal{N}_{m}} \int_{j \in \mathcal{N}_{m}} x_{i, m} x_{j, m} d i d j+Y,
$$

$\beta \geq \gamma>0$, where $Y$ is the quantity of the numeraire. Again, labor is the only factor of production. One unit of the numeraire requires one unit of labor and is produced by perfectively competitive firms. That is, again, $\bar{W}=1$. $A_{i}$ indicates the perceived quality of goods supplied by firm $i$ in any market it is active. Moreover, assume that production of one unit of $x$-goods requires $c_{i}$ units of labor in firm $i$. That is, again, firms may differ in both productivity and perceived product quality at any market location they enter.

From (22), the inverse demand function faced by firm $i \in \mathcal{N}_{m}$ in market $m$ reads

$$
p_{i, m}=A_{i}-\beta x_{i, m}-\gamma X_{m}
$$


where $X_{m}:=\int_{j \in \mathcal{N}_{m}} x_{j, m} d j$ is the total quantity of the $x$-good supplied in market $m$. Firms compete in quantities, correctly taking total output $X_{m}$ as given when maximizing profits at stage $3 .{ }^{12}$ As shown in appendix B, the resulting profits at stage 3 for firm $i \in \mathcal{N}_{m}$ read

$$
\pi_{i, m}=\frac{1}{4 \beta^{2}}\left(\alpha_{i}-\frac{\gamma \Theta_{m}}{2 \beta+\gamma N_{m}}\right)^{2},
$$

where $\alpha_{i}:=A_{i}-c_{i}$ and $\Theta_{m}:=\int_{i \in \mathcal{N}_{m}} \alpha_{i} d i$.

Analogously to the preceding CES-utility example, we have $N_{m}^{*}=N^{*}$ and $\Theta_{m}^{*}=$ $\Theta^{*}$ for all $m$ in an equilibrium. ${ }^{13}$ Again, let $\mathcal{H}=\left\{h^{0}, h^{1}\right\}$, and suppose $\alpha_{i}^{*}=a\left(h^{k}\right) \equiv$ $\alpha^{k}$ and $q_{i}^{*} \equiv q^{k}$ for all $i \in \mathcal{I}^{k}, k=0,1$. Thus, $N^{*}$ is still given by (19). Moreover, in analogy to (20), we have

$$
\Theta^{*}=I^{*}\left(r q^{0}+(1-r) q^{1}\right)\left[r \alpha^{0}+(1-r) \alpha^{1}\right] .
$$

Thus, using (19) and (25), one can rewrite (24) to obtain

$$
\pi_{i, m}=\pi\left(\alpha_{i} \mid z^{*}\right)=\frac{1}{4 \beta^{2}}\left(\alpha_{i}-\frac{\gamma I^{*}\left(r q^{0}+(1-r) q^{1}\right)\left[r \alpha^{0}+(1-r) \alpha^{1}\right]}{2 \beta+\gamma I^{*}\left(r q^{0}+(1-r) q^{1}\right)}\right)^{2},
$$

$i \in \mathcal{N}_{m}$. Note that $\pi\left(\alpha_{i} \mid z^{*}\right)$ is quadratic in $\alpha_{i}$. Again, applying Lemma 1 , the following result emerges from (26).

Proposition 6. (Monopolistic competition with quadratic utility). Under utility specification (22) with $\alpha_{i}=A_{i}-c_{i}$, if $a^{\prime}(\cdot) \geq 0$, then $\mathbf{S}$ is hypersegregated.

For instance, complete segregation by managerial skill occurs if $a\left(\bar{h}_{i}\right)=\bar{h}_{i}$. The same holds as long as $a(\cdot)$ is not "too concave". In fact, the considered linear-demand

\footnotetext{
${ }^{12}$ As stated by Ottaviano and Thisse (1999, p. 10), "a firm correctly neglects its impact on the market, but must explicitly account for the impact of the market on its profit" (italics original). Assuming competition in prices, which requires horizontal differentiation of $x$-goods (i.e. $\beta>\gamma$ ), would not alter the main conclusions from this example.

${ }^{13}$ Generally, markets do not have to be identical ex ante, as long as Assumption 1 is fulfilled. For instance, markets with 'low' demand may just attract fewer firms (or weaker firms in terms of the quality of their intangible assets, respectively). However, applicability of the proposed framework is much simpler by focussing on identical markets ex ante, as in the examples of this section.
} 
model has similar features as often encountered in oligopoly theory, e.g. predicting that given differences in unit costs lead to increasing differences in profits. It is this property, which, typically, renders competition for managerial talent sufficiently intense to induce asymmetric sorting in the present framework.

\section{Relation to Stylized Facts}

This section discusses the empirical relevance of the model with respect to stylized facts regarding the size distribution of firms, and the relation of firm size to profitability, productivity, average managerial skills and managerial remuneration.

(i) Size distribution of firms. A highly skewed size distribution of firms and establishments within industries has been frequently found in numerous studies. Whereas the early literature hypothesized some stochastic growth process of firms to generate this outcome, subsequent research has either incorporated profit-maximization into models of stochastic firm growth or studied market dynamics of firms which differ in an innate characteristic. (For an excellent survey, see Sutton, 1997.) In contrast, we have assumed that potential entrants in the economy are ex ante identical and there are no random shocks. Nevertheless, the model is capable to explain a skewed size distribution of firms in two dimensions: first, in gross profits (which are naturally related to output, employment levels or sales), and, second, in the firms' total number of establishments (i.e., market ranges). Moreover, under plausible conditions, the distribution of profits at the plant-level ("profits at stage 3") is skewed. To see this, recall from Lemma 1 that under the plausible property that single-market profits $\pi\left(\alpha_{i} \mid \cdot\right)$ (profits at stage 3 ) are strictly convex in the firm-specific quality of intangible assets $\alpha_{i}$, also gross profits $\Pi\left(\alpha_{i} \mid \cdot\right)$ (profits at stage 2) are strictly convex in $\alpha_{i}$. Moreover, under weak conditions, this property gives rise to both strict convexity of firms' market ranges $q_{i}^{*}$ in $\alpha_{i}$ and hypersegregation of the equilibrium configuration of manager assignments, according to Lemma 1 and Proposition 3, respectively. Thus, the size distribution of firms and establishments tend to be convex mappings of the distribution of managerial skills in the upper tale of the skill distribution 
(which contains all types actually assigned as managers in equilibrium). In other words, small differences in the firms' managerial skill levels become magnified into increasingly larger differences in both profits (at stages 2 and 3) and market ranges. Thus, the size distribution of firms and plants tends to be skewed to the right.

(ii) Firm size, profitability and market shares. As pointed out by Schmalensee (1989; stylized facts 4.11-4.13), in samples with many industries, U.S. firms (and business units) with higher market shares are also more profitable. Moreover, this result seems to be driven mainly by manufacturing industries with high advertisingto-sales ratios. Conventional measures of accounting profitability often treat outlays for advertising, R\&D and the development of firm-specific human capital as current expenses, although these raise future capabilities of firms. This practice, which (at least in the U.S.) is particularly adopted by large firms (Schmalensee, 1989; stylized fact 3.2), understates assets of firms. It has been argued that exactly this is the source of the often observed positive size-profitability relationship (Salamon (1985)). All of these findings fit well into the preceding analysis. According to the model, some firms are larger and have higher gross profits than others because they incur higher sunk costs for developing intangible assets. Although 'economic' profitability is the same across firms, accounting profitability may differ due to different accounting practices. Moreover, endogenous sunk costs (e.g., for advertising) are naturally high in industries in which intangible assets (like trademarks) play a significant role. This is consistent with a positive size-profitability relationship in advertising-intensive industries only.

(iii) Firm size, productivity and marginal costs. As reviewed by Bartelsman and Doms (2000), there is a substantial degree of heterogeneity among both firms and establishments with respect to productivity levels. Longitudinal microdata suggest that these differences are related to differences in manager quality. Moreover, Roberts and Supina (2000) report a negative correlation between marginal costs and firm size among U.S. manufacturing firms. These findings are consistent with our theoretical result that the quality of management, which, e.g., determines the productivity of plants in the model, positively affects the size of firms in both dimensions 
(gross profits and market range) and the size of plants.

(iv) Sorting of managers. Evidence from matched employer-employee data strongly suggests that larger firms employ workers with higher average skill levels (e.g., Abowd, Kramarz and Margolis (1999), Troske (1999)). O'Shaughnessy, Levine and Capelli (2001) explicitly look at a measure for managerial skills, which is an index combining formal education with job requirements like problem-solving skills and predictability of tasks, known as 'Hay points'. They find that average managerial skill levels substantially differ across firms. ${ }^{14}$ This supports the asymmetric sorting hypothesis of managerial skills elaborated in this paper.

(v) Firm size and manager remuneration. Finally, there is overwhelming evidence for a positive relationship between firm size (or establishment size) and wages. According to studies based on matched employer-employee data, a large part of this premium seems to be related to imperfectly observable skills, like managerial talent, together with a sorting of good managers in large firms. For instance, Troske (1999) controls for many firm-specific characteristics which have been suggested by economic theory on size-wage differentials, still finding a substantial impact of firm size on wages. Also at the CEO level, larger firms pay substantially higher wages (Conyon and Murphy (2000)). Moreover, O'Shaughnessy, Levine and Capelli (2001) find that their measure of managerial skills ('Hay points') is a good predictor for wages. In fact, our model predicts that the earnings distribution for managers tends to be skewed to the right. To see this, recall that, according to the model, gross profits per manager are equal to the average earnings of managers within firms. Thus, for instance, under complete segregation of firms by managerial skill, the distribution of manager wages mimics the distribution of gross profits. As argued above, the latter tends to be skewed to the right. This magnification of skill differences in increasingly larger earning differentials resembles the famous superstar economy of Rosen (1981), however, for a different reason. Rosen (1981) derives a strictly

\footnotetext{
${ }^{14}$ Even when controlling for job level and function, the authors report a standard deviation of the firm effect in a regression of Hay points on several controls of 13.7 percent in 1986 and 12.7 percent in 1992.
} 
convex mapping from individual ability to individual earnings from the ability of more talented individuals (acting as atomistic firms) to cover a wider range of markets. In Rosen (1982), a similar magnification effect arises with respect to manager remuneration due to a complementarity between supervisory skills and the span of control. In contrast, in the present analysis, managers develop intangible assets; and differences in the firms' quality of intangible assets tend to become magnified in profit differences. In turn, these profit differences determine earnings differences of managers.

\section{Conclusion}

This paper has focussed on the interaction between product market characteristics and the market for managerial skills. Intangible assets like the organizational structure of a firm, firm-specific knowledge, product design, trademarks, etc., play a key role for the performance of firms. Development of intangible assets is the responsibility of management. Consequently, and according to the main hypothesis of this paper, managerial quality is a crucial factor for the productivity of firms and the perceived quality of products. It has been argued that, under free entry of ex ante identical firms and geographical non-rivalry of intangible assets, the nature of product market competition determines how heterogeneous managerial skills sort into head departments. In turn, this sorting process determines the goods market structure at single locations and the size distribution of firms in the economy.

Standard imperfect competition models imply that given differences among firms in productivity or product quality transmit into increasingly larger differences in profits. This property is related to a high intensity of product market competition. It has been shown that, under this condition, firms tend to differ endogenously in two dimensions of firm size: gross profits (typically related to a firms' output, sales or employment level) and the number of plants (market ranges). Thus, paradoxically, if symmetry breaks down due to an increase in the intensity of product market competition, "global players" with high market power may emerge in the first place. 
In particular, the main results of this paper are consistent with the well-known regularity that the size distribution of firms and establishments within industries is skewed to the right. Moreover, the model predicts that firm size is positively related to productivity, profitability, average managerial skills and average managerial wages. Thus, the model is not only capable to explain why firms differ in general, but provides a unified framework which is consistent with specific observations about market structures, sorting of managers in firms and managerial remuneration.

\section{Appendix}

\section{A. Proofs}

Proof of Proposition 1. Part (i) is proven first. If $0<\tilde{q}_{i}<1$, such that condition (4) is binding and $Q^{\prime \prime}\left(\tilde{q}_{i}\right)>0$ must hold, we have

$$
\frac{\partial \tilde{q}_{i}}{\partial \alpha_{i}}=\frac{\partial \pi\left(\alpha_{i} \mid \tilde{z}\right) / \partial \alpha_{i}}{Q^{\prime \prime}\left(\tilde{q}_{i}\right)}>0
$$

according to $\frac{\partial \pi\left(\alpha_{i} \mid \cdot\right)}{\partial \alpha_{i}}>0$ from part (i) of Assumption 1 and the implicit function theorem. To prove part (ii), note that, whenever $0<\tilde{q}_{i}<1$,

$$
\frac{\partial \Pi\left(\alpha_{i} \mid \tilde{z}\right)}{\partial \alpha_{i}}=\frac{\partial \tilde{q}_{i}}{\partial \alpha_{i}}\left[\pi\left(\alpha_{i} \mid \tilde{z}\right)-Q^{\prime}\left(\tilde{q}_{i}\right)\right]+\tilde{q}_{i} \frac{\partial \pi\left(\alpha_{i} \mid \tilde{z}\right)}{\partial \alpha_{i}}
$$

is strictly positive, according to $\frac{\partial \pi\left(\alpha_{i} \mid \cdot\right)}{\partial \alpha_{i}}>0$, condition (4) and $\frac{\partial \tilde{q}_{i}}{\partial \alpha_{i}}>0$ from part (i). If $\tilde{q}_{i}=1$, then part (ii) directly follows from $\frac{\partial \pi\left(\alpha_{i} \mid \cdot\right)}{\partial \alpha_{i}}>0$. This concludes the proof.

Proof of Lemma 1. First, note that

$$
\begin{aligned}
\frac{\partial^{2} \Pi\left(\alpha_{i} \mid \tilde{z}\right)}{\partial \alpha_{i}^{2}}= & \frac{\partial \tilde{q}_{i}}{\partial \alpha_{i}} \frac{\partial \pi\left(\alpha_{i} \mid \tilde{z}\right)}{\partial \alpha_{i}}+\tilde{q}_{i} \frac{\partial^{2} \pi\left(\alpha_{i} \mid \tilde{z}\right)}{\partial \alpha_{i}^{2}}+ \\
& \frac{\partial^{2} \tilde{q}_{i}}{\partial \alpha_{i}^{2}}\left[\pi\left(\alpha_{i} \mid \tilde{z}\right)-Q^{\prime}\left(\tilde{q}_{i}\right)\right]+\frac{\partial \tilde{q}_{i}}{\partial \alpha_{i}}\left[\frac{\partial \pi\left(\alpha_{i} \mid \tilde{z}\right)}{\partial \alpha_{i}}-Q^{\prime \prime}\left(\tilde{q}_{i}\right) \frac{\partial \tilde{q}_{i}}{\partial \alpha_{i}}\right]
\end{aligned}
$$

according to (A.2). If $\tilde{q}_{i}<1$, then $\frac{\partial \tilde{q}_{i}}{\partial \alpha_{i}}>0$ and both terms in square brackets vanish, according to (4) and (A.1), respectively. If $\tilde{q}_{i}=1$, the latter two summands in (A.3) also vanish. Thus, $\frac{\partial \tilde{q}_{i}}{\partial \alpha_{i}} \geq 0$ (from part (ii) of Proposition 1) implies that $\frac{\partial^{2} \Pi\left(\alpha_{i} \mid \tilde{z}\right)}{\partial \alpha_{i}^{2}}>0$ 
if $\pi\left(\alpha_{i} \mid \tilde{z}\right)$ is strictly convex in $\alpha_{i}$. Second, recall that $\tilde{q}_{i}<1$ implies that $Q^{\prime \prime}\left(\tilde{q}_{i}\right)>0$ must hold and use (A.1) to obtain

$$
\frac{\partial^{2} \tilde{q}_{i}}{\partial \alpha_{i}^{2}}=\frac{1}{Q^{\prime \prime}\left(\tilde{q}_{i}\right)^{2}}\left(\frac{\partial^{2} \pi\left(\alpha_{i} \mid \tilde{z}\right)}{\partial \alpha_{i}^{2}} Q^{\prime \prime}\left(\tilde{q}_{i}\right)-\left(\frac{\partial \pi\left(\alpha_{i} \mid \tilde{z}\right)}{\partial \alpha_{i}}\right)^{2} \frac{Q^{\prime \prime \prime}\left(\tilde{q}_{i}\right)}{Q^{\prime \prime}\left(\tilde{q}_{i}\right)}\right)
$$

Thus, $\frac{\partial^{2} \tilde{q}_{i}}{\partial \alpha_{i}^{2}}>0$ if $\tilde{q}_{i}<1, \frac{\partial^{2} \pi\left(\alpha_{i} \mid \tilde{z}\right)}{\partial \alpha_{i}^{2}}>0$ and $Q^{\prime \prime \prime}\left(\tilde{q}_{i}\right) \leq 0$. This concludes the proof.

Proof of Proposition 2: Part (i) is proven first. At stage 1, taking $z^{*}$ as given, each firm $i \in \mathcal{I}$ chooses an assignment function $\tilde{g}_{i} \in \tilde{G}$ (determining $\bar{h}_{i}$ and $\left.\alpha_{i}=a\left(\bar{h}_{i}\right)\right)$ by solving

$$
\begin{aligned}
& \max _{\tilde{g}(h), h \in \mathcal{H}}\left\{f\left(\frac{1}{s} \sum_{h \in \mathcal{H}} h \tilde{g}(h) \mid z^{*}\right)-\sum_{h \in \mathcal{H}} \tilde{g}(h) w(h)\right\} \\
& \text { s.t. } \tilde{g}(h) \geq 0 \text { for all } h \in \mathcal{H} \text {, and } \sum_{h \in \mathcal{H}} \tilde{g}(h)=s .
\end{aligned}
$$

Setting up the Kuhn-Tucker problem with multiplier $\lambda_{i}$ on the constraint $\sum_{h \in \mathcal{H}} \tilde{g}(h)=$ $s$ for firm $i \in \mathcal{I}$, the necessary optimality conditions for $\tilde{g}_{i}(h), h \in \mathcal{H}$, are given by

$$
\frac{\partial f\left(\bar{h}_{i}^{*} \mid z^{*}\right)}{\partial \bar{h}_{i}} \frac{h}{s}-w(h) \leq \lambda_{i}
$$

with strict equality if $\tilde{g}_{i}^{*}(h)>0$. This implies the following. Either each firm $i$ hires only one type of manager or for any two different types $h, \hat{h} \in S_{i}$, we have

$$
w(h)-w(\hat{h})=\frac{\partial f\left(\bar{h}_{i}^{*} \mid z^{*}\right)}{\partial \bar{h}_{i}} \frac{h-\hat{h}}{s} .
$$

Multiplying both sides of (A.6) with $\tilde{g}_{i}^{*}(h)$ and summing yields

$$
s \lambda_{i}=\frac{\partial f\left(\bar{h}_{i}^{*} \mid z^{*}\right)}{\partial \bar{h}_{i}} \bar{h}_{i}-\sum_{h \in \mathcal{H}} w(h) \tilde{g}_{i}^{*}(h)
$$

where $\sum_{h \in \mathcal{H}} \tilde{g}_{i}^{*}(h)=s$ and $\bar{h}_{i}^{*}=\frac{1}{s} \sum_{h \in \mathcal{H}} h \tilde{g}_{i}^{*}(h)$ have been used. Substituting (A.8) into (A.6) and observing condition (a) of Definition 2 yields (10). This proves part (i).

In order to prove part (ii), first, suppose there exist types $h \in \mathcal{S}$ and $\hat{h} \notin \mathcal{S}$ such that $h<\hat{h}$. It is now shown that this is only possible if $w(h)<w(\hat{h})$. For this end, suppose $w(h) \geq w(\hat{h})$ and suppose firm $i$ replaces some managers of type $h$ by some 
of type $\hat{h}$, choosing an assignment function $g_{i}^{\prime} \in \tilde{G}$ instead of $g_{i}^{*} \in \tilde{G}$. Total wage costs of firm $i$ are then given by

$$
\begin{aligned}
\sum_{h \in \mathcal{H}} w(h) \tilde{g}_{i}^{\prime}(h)= & \sum_{h \in \mathcal{H}} w(h) \tilde{g}_{i}^{*}(h)+ \\
& w(\hat{h}) g_{i}^{\prime}(\hat{h})+w(h)\left[\tilde{g}_{i}^{\prime}(h)-\tilde{g}_{i}^{*}(h)\right] .
\end{aligned}
$$

Using $g_{i}^{\prime}(\hat{h})=g_{i}^{*}(h)-g_{i}^{\prime}(h)$ one finds $\sum_{h \in \mathcal{H}} w(h) \tilde{g}_{i}^{\prime}(h) \leq \sum_{h \in \mathcal{H}} w(h) \tilde{g}_{i}^{*}(h)$ if $w(h) \geq$ $w(\hat{h})$. Moreover, $\bar{h}_{i}^{\prime}=\frac{1}{s} \sum_{h \in \mathcal{H}} h \tilde{g}_{i}^{\prime}(h)>\bar{h}_{i}^{*}$ implies $f\left(\bar{h}_{i}^{\prime} \mid z^{*}\right)>f\left(\bar{h}_{i}^{*} \mid z^{*}\right)$. Hence, $f\left(\bar{h}_{i}^{*} \mid z^{*}\right)-\sum_{h \in \mathcal{H}} w(h) \tilde{g}_{i}^{*}(h)<f\left(\bar{h}_{i}^{\prime} \mid z^{*}\right)-\sum_{h \in \mathcal{H}} w(h) \tilde{g}_{i}^{\prime}(h)$. As this violates (9) and, thus, equilibrium condition (b) of Definition 2, we have $w(h)<w(\hat{h})=\bar{W}$, where the latter equation follows from $\hat{h} \notin \mathcal{S}$. However, this is impossible because type $h$ would then prefer not to work as manager. Thus, $h \geq \hat{h}$ for all $h \in \mathcal{S}$ and $\hat{h} \notin \mathcal{S}$, i.e., there exists a cut-off level $h^{\text {min }} \in \mathcal{H}$ such that $h \geq h^{\text {min }}$ for all $h \in \mathcal{S}$. With $\mathcal{H}=\left\{h^{0}, h^{1}, \ldots, h^{K}\right\}$, the set $\mathcal{S}$ of types assigned as manager equals $\left\{h^{\mathrm{min}}, \ldots, h^{K}\right\}$, $h^{\min } \geq h^{0}$.

In order to prove part (iii), note that $w\left(h^{\mathrm{min}}\right) \geq \bar{W}$, with strict equality if not all types $h^{\text {min }}$ are managers, according to condition (c) of Definition 2. As some workers of type $h^{\text {min }}$ are employed as managers (note that $h^{\text {min }}$ is the least skilled type of worker assigned as manager), $w(h)>\bar{W}$ for all $h>h^{\text {min }}$ directly follows from part (i).

Finally, to prove part (iv), note that (10) implies $w\left(\bar{h}_{i}^{*}\right) \geq f\left(\bar{h}_{i}^{*} \mid z^{*}\right) / s$ with strict equality if $\bar{h}_{i}^{*} \in S_{i}$, according to part (i). Thus, if $S_{i}=\left\{\bar{h}_{i}^{*}\right\}$, part (iv) is trivial. Now suppose $S_{i} \neq\left\{\bar{h}_{i}^{*}\right\}$ and note that $\bar{h}_{i}^{*} \in\left[h^{\text {min }}, h^{K}\right]$, according to part (ii). Now suppose that there is an equilibrium, with assignment functions $\tilde{g}_{i}^{\prime} \in \tilde{G}$, average managerial skill levels $\bar{h}_{i}^{\prime}=\frac{1}{s} \sum_{h \in \mathcal{H}} h \tilde{g}_{i}^{\prime}(h), i \in \mathcal{I}$, and corresponding mapping $z^{\prime}=\left(\boldsymbol{\alpha}^{\prime}, \mathbf{q}^{\prime}\right)$, such that $w\left(\bar{h}_{i}^{\prime}\right)>f\left(\bar{h}_{i}^{\prime} \mid z^{\prime}\right) / s$ for $\bar{h}_{i}^{\prime} \notin S_{i}$. Then any firm $j \neq i$ which employs $\tilde{g}_{j}^{\prime}\left(\bar{h}_{i}^{\prime}\right)>0$ managers of type $\bar{h}_{i}^{\prime}$ would prefer to replace this type by hiring $\varepsilon \tilde{g}_{i}^{\prime}(h)$ managers from each type $h \in S_{i}$, with $\varepsilon=\tilde{g}_{j}^{\prime}\left(\bar{h}_{i}^{\prime}\right) / s$. To see this, note that wage cost for these types 
read

$$
\begin{aligned}
\sum_{h \in S_{i}} w(h) \varepsilon \tilde{g}_{i}^{\prime}(h) & =\frac{\tilde{g}_{j}^{\prime}\left(\bar{h}_{i}^{\prime}\right)}{s} \sum_{h \in S_{i}} w(h) \tilde{g}_{i}^{\prime}(h) \\
& =\frac{\tilde{g}_{j}^{\prime}\left(\bar{h}_{i}^{\prime}\right)}{s} f\left(\bar{h}_{i}^{\prime} \mid z^{\prime}\right),
\end{aligned}
$$

according to $(7)$. Also note that wage cost $w\left(\bar{h}_{i}^{\prime}\right) \tilde{g}_{j}\left(\bar{h}_{i}^{\prime}\right)$ are saved. Thus, net wage cost savings from such a replacement are given by $\left[w\left(\bar{h}_{i}^{\prime}\right)-f\left(\bar{h}_{i}^{\prime} \mid z^{\prime}\right) / s\right] \tilde{g}_{j}^{\prime}\left(\bar{h}_{i}^{\prime}\right)$, which is strictly positive if $w\left(\bar{h}_{i}^{\prime}\right)>f\left(\bar{h}_{i}^{\prime} \mid z^{\prime}\right) / s$ for $\bar{h}_{i}^{\prime} \notin S_{i}$, i.e., there would be a profitable deviation. However, according to condition (b) of Definition 2, this is inconsistent with an equilibrium. Hence, $w\left(\bar{h}_{i}^{*}\right)=f\left(\bar{h}_{i}^{*} \mid z^{*}\right) / s$. This concludes the proof.

Proof of Proposition 3. Consider strict convexity of $f\left(\bar{h}_{i} \mid z^{*}\right)$ in $\bar{h}_{i}$ for all $i$ (at equilibrium levels) first. Suppose $S_{i} \neq\left\{\bar{h}_{i}^{*}\right\}$ for some $i$, i.e., there exist $h, \hat{h} \in S_{i}$ such that $\hat{h}>h$. If firm $i$ replaces some managers of type $h$ by some of type $\hat{h}$ (i.e., firm $i$ chooses an assignment function $\tilde{g}_{i}^{\prime} \in \tilde{G}$ instead of $\left.\tilde{g}_{i}^{*} \in \tilde{G}\right)$ its average managerial skill rises from $\bar{h}_{i}^{*}$ to $\bar{h}_{i}^{\prime}>\bar{h}_{i}^{*}$. (Note that such a replacement is possible since $h, \hat{h} \in S_{i}$ implies $\tilde{g}_{i}^{*}(\hat{h})<\sum_{h \in S_{i}} \tilde{g}_{i}^{*}(h)=s$ and $s \leq g(h)$ for all $h \in \mathcal{H}$ by assumption; thus, $\tilde{g}_{i}^{*}(\hat{h})<g(\hat{h})$.) Given $z^{*}$, total wage costs for managerial workers in firm $i$ then read

$$
\begin{aligned}
\sum_{h \in S_{i}} w(h) \tilde{g}_{i}^{\prime}(h)= & \sum_{h \in S_{i}} w(h) \tilde{g}_{i}^{*}(h)+ \\
& w(h)\left[\tilde{g}_{i}^{\prime}(h)-\tilde{g}_{i}^{*}(h)\right]+w(\hat{h})\left[\tilde{g}_{i}^{\prime}(\hat{h})-\tilde{g}_{i}^{*}(\hat{h})\right] \\
= & f\left(\bar{h}_{i}^{*} \mid z^{*}\right)+\frac{\partial f\left(\bar{h}_{i}^{*} \mid z^{*}\right)}{\partial \bar{h}_{i}} \frac{h-\hat{h}}{s}\left[\tilde{g}_{i}^{\prime}(h)-\tilde{g}_{i}^{*}(h)\right],
\end{aligned}
$$

where

$$
\tilde{g}_{i}^{\prime}(h)-\tilde{g}_{i}^{*}(h)=-\left[\tilde{g}_{i}^{\prime}(\hat{h})-\tilde{g}_{i}^{*}(\hat{h})\right],
$$

(7) and (A.7) have been used. Using $\bar{h}_{i}^{\prime}=\frac{1}{s} \sum_{h \in S_{i}} h \tilde{g}_{i}^{\prime}(h)$ and $\bar{h}_{i}^{*}=\frac{1}{s} \sum_{h \in S_{i}} h \tilde{g}_{i}^{*}(h)$ together with (A.12) implies $\bar{h}_{i}^{\prime}-\bar{h}_{i}^{*}=\frac{h-\hat{h}}{s}\left[\tilde{g}_{i}^{\prime}(h)-\tilde{g}_{i}^{*}(h)\right]$. Hence,

$$
\sum_{h \in S_{i}} w(h) \tilde{g}_{i}^{\prime}(h)=f\left(\bar{h}_{i} \mid z^{*}\right)+\frac{\partial f\left(\bar{h}_{i} \mid z^{*}\right)}{\partial \bar{h}_{i}}\left(\bar{h}_{i}^{\prime}-\bar{h}_{i}^{*}\right)
$$


Moreover, gross profits of firm $i$ now read $f\left(\bar{h}_{i}^{\prime} \mid z^{*}\right)$. According to condition (b) of Definition 2, the considered deviation must not to be profitable for firm $i$, i.e.,

$$
f\left(\bar{h}_{i}^{\prime} \mid z^{*}\right) \leq f\left(\bar{h}_{i} \mid z^{*}\right)+\frac{\partial f\left(\bar{h}_{i} \mid z^{*}\right)}{\partial \bar{h}_{i}}\left(\bar{h}_{i}^{\prime}-\bar{h}_{i}\right)
$$

which can be rewritten as $\frac{f\left(\bar{h}_{i}^{\prime} \mid z^{*}\right)-f\left(\bar{h}_{i} \mid z^{*}\right)}{\bar{h}_{i}^{\prime}-\bar{h}_{i}} \leq \frac{\partial f\left(\bar{h}_{i} \mid z^{*}\right)}{\partial \bar{h}_{i}}$. However, this is impossible if $f\left(\bar{h}_{i} \mid z^{*}\right)$ is strictly convex in $\bar{h}_{i}$; thus, $S_{i}=\left\{\bar{h}_{i}^{*}\right\}$. In view of Definition 3 , this proves that the configuration of manager assignments $\mathbf{S}$ is hypersegregated under strict convexity of $f\left(\bar{h}_{i} \mid z^{*}\right)$ in $\bar{h}_{i}$ (at equilibrium levels).

It remains to be shown that $\bar{h}_{i}^{*}=\bar{h}^{*}$ for all $i$ in any equilibrium if $f\left(\bar{h}_{i} \mid z^{*}\right)$ is strictly concave in $\bar{h}_{i}$ (at equilibrium levels). To see this, note that (10) implies

$$
s w\left(\bar{h}_{i}^{*}\right)=f\left(\bar{h}_{i}^{*} \mid z^{*}\right) \geq f\left(\bar{h}_{j}^{*} \mid z^{*}\right)+\frac{\partial f\left(\bar{h}_{j}^{*} \mid z^{*}\right)}{\partial \bar{h}_{j}}\left(\bar{h}_{i}^{*}-\bar{h}_{j}^{*}\right)
$$

and

$$
s w\left(\bar{h}_{j}^{*}\right)=f\left(\bar{h}_{j}^{*} \mid z^{*}\right) \geq f\left(\bar{h}_{i}^{*} \mid z^{*}\right)+\frac{\partial f\left(\bar{h}_{i}^{*} \mid z^{*}\right)}{\partial \bar{h}_{i}}\left(\bar{h}_{j}^{*}-\bar{h}_{i}^{*}\right),
$$

respectively. Without loss of generality, suppose $\bar{h}_{i}^{*}>\bar{h}_{j}^{*}$ for some $i, j \in \mathcal{I}, i \neq j$. (A.15) and (A.16) then imply

$$
\frac{\partial f\left(\bar{h}_{i}^{*} \mid z^{*}\right)}{\partial \bar{h}_{i}} \geq \frac{f\left(\bar{h}_{i}^{*} \mid z^{*}\right)-f\left(\bar{h}_{j}^{*} \mid z^{*}\right)}{\bar{h}_{i}^{*}-\bar{h}_{j}^{*}} \geq \frac{\partial f\left(\bar{h}_{j}^{*} \mid z^{*}\right)}{\partial \bar{h}_{j}} .
$$

However, $\frac{\partial f\left(\bar{h}_{i}^{*} \mid z^{*}\right)}{\partial \bar{h}_{i}}<\frac{\partial f\left(\bar{h}_{j}^{*} \mid z^{*}\right)}{\partial \bar{h}_{j}}$ if $\bar{h}_{i}^{*}>\bar{h}_{j}^{*}$ and $f\left(\bar{h}_{i} \mid z^{*}\right)$ is strictly concave in $\bar{h}_{i}$. Thus, $\bar{h}_{i}^{*} \neq \bar{h}_{j}^{*}$ for $i, j \in \mathcal{I}, i \neq j$ can never hold in an equilibrium. This concludes the proof.

Proof of Proposition 4. As argued in Remark 1, Saint-Paul (2001) studies a special case of the present analysis in which $f\left(\bar{h}_{i} \mid z^{*}\right)=\pi\left(a\left(\bar{h}_{i}\right) \mid z^{*}\right)=a\left(\bar{h}_{i}\right)$ for all $i \in \mathcal{I}$ and $\mathcal{I}=[0,1 / s]$. Noting that $z^{*}$ is taken as given by firms at stage 1 , it is easy to check that the formal structure of the present analysis fulfills the presumptions in Saint-Paul (2001, Proposition 2). The result can, thus, directly deducted from his analysis. 


\section{B. Derivation of Equations (17) and (24)}

Derivation of equation (17): Remember that, at any market $m \in[0,1]$, the production function of each firm $i \in \mathcal{N}_{m}$ is given by

$$
x_{i, m}=\beta_{i} l_{i, m}
$$

where $l_{i, m}$ is the amount of production labor employed in firm at market $m$. Thus, with $\bar{W}=1$, firm $i \in \mathcal{N}_{m}$ solves $\max _{p_{i, m}}\left[\left(p_{i, m}-1 / \beta_{i}\right) x_{i, m}\right]$ s.t. (16). Hence, the profit-maximizing price for variety $i$ at market $m$ is given by

$$
p_{i, m}=\frac{\sigma}{\sigma-1} \cdot \frac{1}{\beta_{i}} .
$$

Using both equations (16) and (B.2), for any $i, j \in \mathcal{N}_{m}$, we have $\frac{x_{i, m}}{x_{j, m}}=\left(\frac{\gamma_{i}}{\gamma_{j}}\right)^{\sigma-1}\left(\frac{\beta_{i}}{\beta_{j}}\right)^{\sigma}$. Moreover, according to production function (B.1), we have $\frac{x_{i, m}}{x_{j, m}}=\frac{\beta_{i} l_{i, m}}{\beta_{j} l_{j, m}}$. Thus, we obtain

$$
\frac{l_{i, m}}{l_{j, m}}=\left(\frac{\beta_{i} \gamma_{i}}{\beta_{j} \gamma_{j}}\right)^{\sigma-1}
$$

$i, j \in \mathcal{N}_{m}$. The aggregate amount of production labor $L_{m}$ employed in market $m$ is given by $L_{m}=\int_{j \in \mathcal{N}_{m}} l_{j, m} d j$. According to (B.3), this is equivalent to $L_{m}=$ $l_{i, m} \alpha_{i}^{1-\sigma} \int_{j \in \mathcal{N}_{m}}\left(\alpha_{j}\right)^{\sigma-1} d j$, where $\alpha_{i}=\beta_{i} \gamma_{i}, i \in \mathcal{I}$, has been used. Hence,

$$
l_{i, m}=\frac{L_{m} \alpha_{i}^{\sigma-1}}{\int_{j \in \mathcal{N}_{m}}\left(\alpha_{j}\right)^{\sigma-1} d j} .
$$

The profit of firm $i \in \mathcal{N}_{m}$ at stage 3 is given by $\left(p_{i, m}-1 / \beta_{i}\right) x_{i, m}=\frac{l_{i, m}}{\sigma-1}$, according to (B.1) and (B.2). Finally, use (B.4) to confirm equation (17).

Derivation of equation (24): Under monopolistic competition (in quantities) with utility function (22), at stage 3 , firm $i \in \mathcal{N}_{m}$ solves $\max _{x_{i, m}}\left[\left(p_{i, m}-c_{i}\right) x_{i, m}\right]$ s.t. (23), taking total output $X_{m}$ as given. The first-order condition implies

$$
x_{i, m}=\frac{\alpha_{i}-\gamma X_{m}}{2 \beta}
$$

where $\alpha_{i}=A_{i}-c_{i}$. Integrating over all $i \in \mathcal{N}_{m}$, where $\mathcal{N}_{m}$ has measure $N_{m}$, and solving for $X_{m}$ yields $X_{m}=\frac{\Theta_{m}}{2 \beta+\gamma N_{m}}$, where $\Theta_{m}=\int_{i \in \mathcal{N}_{m}} \alpha_{i} d i$. Substituting this into 
(B.5) yields $x_{i, m}=\frac{1}{2 \beta}\left(\alpha_{i}-\frac{\gamma \Theta_{m}}{2 \beta+\gamma N_{m}}\right)$. Substituting the latter two expressions, for $X_{m}$ and $x_{i, m}$, into $(23)$ yields $p_{i, m}-c_{i}=\frac{1}{2 \beta}\left(\alpha_{i}-\frac{\gamma \Theta_{m}}{2 \beta+\gamma N_{m}}\right)$. Noting that $\pi_{i, m}=$ $\left(p_{i, m}-c_{i}\right) x_{i, m}$ confirms equation $(24)$.

\section{Derivation and Existence of Equilibrium}

This appendix illustrates in an exemplary way how to prove existence of an equilibrium (also sketching its full derivation) in the CES-utility case of section 4.1.

First, as in the main text, consider a hypersegregated equilibrium configuration of manager assignments with two types of firms. In such an equilibrium, we have $I^{0}=\hat{g}\left(h^{0}\right) / s$ and the equilibrium measure of firms $I^{*}$ reads

$$
I^{*}=\frac{\hat{g}\left(h^{0}\right)+g\left(h^{1}\right)}{s},
$$

according to equation (11). Thus, the equilibrium share of firms with low-skilled managers $r=I^{0} / I^{*}$ is given by

$$
r=\frac{\hat{g}\left(h^{0}\right)}{\hat{g}\left(h^{0}\right)+g\left(h^{1}\right)} .
$$

The cost function $Q(\cdot)$ for entering single markets is assumed to have a simple isoelastic form:

$$
Q\left(q_{i}\right)=F\left(q_{i}\right)^{\eta}
$$

with $F \geq 0$ and $\eta \geq 1$. Note that $F=0$ or $\eta=1$ implies $q_{i}^{*}=1$ for all $i \in \mathcal{I}$. Suppose, however, for the sake of concreteness, that all firms have limited market ranges, i.e., $q_{i}^{*} \in(0,1), i \in \mathcal{I}$. Note that, with limited market ranges, $q_{i}^{*}$ fulfills $\pi\left(\alpha_{i} \mid z^{*}\right)=Q^{\prime}\left(q_{i}^{*}\right)$, according to Definition 1 and condition (4). Thus, using (C.3), we have

$$
q_{i}^{*}=\left(\frac{\pi\left(\alpha_{i}^{*} \mid z^{*}\right)}{F \eta}\right)^{\frac{1}{\eta-1}}
$$

if $\pi\left(\alpha_{i} \mid z^{*}\right)<F \eta$. Consequently,

$$
f\left(\bar{h}_{i} \mid z^{*}\right)=F(\eta-1)\left(\frac{\pi\left(a\left(\bar{h}_{i}\right) \mid z^{*}\right)}{F \eta}\right)^{\frac{\eta}{\eta-1}}
$$


according to (1), (3) and (6). Combining (21) and (C.5) implies

$$
\begin{aligned}
f\left(\bar{h}_{i} \mid z^{*}\right) & =\Gamma\left(\frac{a\left(\bar{h}_{i}\right)^{\sigma-1}\left(1-s I^{*}\right)}{I^{*}\left(r q^{0}+(1-r) q^{1}\right)\left[r\left(\alpha^{0}\right)^{\sigma-1}+(1-r)\left(\alpha^{1}\right)^{\sigma-1}\right]}\right)^{\frac{\eta}{\eta-1}} \\
& =\Gamma\left(\frac{a\left(\bar{h}_{i}\right)^{\sigma-1}\left(1-\hat{g}\left(h^{0}\right)-g\left(h^{1}\right)\right) s}{\left(\hat{g}\left(h^{0}\right) q^{0}+(1-r) q^{1}\right)\left[\hat{g}\left(h^{0}\right) a\left(h^{0}\right)^{\sigma-1}+g\left(h^{1}\right) a\left(h^{1}\right)^{\sigma-1}\right]}\right)^{\frac{\eta}{\eta-1}}
\end{aligned}
$$

$\Gamma \equiv(\eta-1)\left(\frac{F}{\eta^{\eta}(\sigma-1)^{\eta}}\right)^{\frac{1}{\eta-1}}$, where $\alpha^{k}=a\left(h^{k}\right), k=0,1$, (C.1) and (C.2) have been used for the latter equation.

Next, recall that $\alpha_{i}^{*}=\alpha^{k}=a\left(h^{k}\right)$ and $q_{i}^{*}=q^{k}$ for all $i \in \mathcal{I}^{k}, k=0,1$. Thus, combining equations (21) and (C.4), equilibrium market ranges $q^{0}$ and $q^{1}$ fulfill

$$
\begin{aligned}
q^{k} & =\left(\frac{a\left(h^{k}\right)^{\sigma-1}\left(1-s I^{*}\right)}{I^{*}\left(r q^{0}+(1-r) q^{1}\right)\left[r a\left(h^{0}\right)^{\sigma-1}+(1-r) a\left(h^{1}\right)^{\sigma-1}\right] F \eta(\sigma-1)}\right)^{\frac{1}{\eta-1}}(\mathrm{C} .7) \\
& =\left(\frac{a\left(h^{k}\right)^{\sigma-1}\left(1-\hat{g}\left(h^{0}\right)-g\left(h^{1}\right)\right) s\left(\hat{g}\left(h^{0}\right)+g\left(h^{1}\right)\right)}{\left(\hat{g}\left(h^{0}\right) q^{0}+g\left(h^{1}\right) q^{1}\right)\left[\hat{g}\left(h^{0}\right) a\left(h^{0}\right)^{\sigma-1}+g\left(h^{1}\right) a\left(h^{1}\right)^{\sigma-1}\right] F \eta(\sigma-1)}\right)^{\frac{1}{\eta-1}}
\end{aligned}
$$

$k=0,1$, where (C.1) and (C.2) have been used for the latter equation.

Note that $\hat{g}\left(h^{0}\right)<g\left(h^{0}\right)$ in the supposed equilibrium, as some workers of type $h^{0}$ must be employed as production worker. Thus, $w\left(h^{0}\right)=\bar{W}=1$, according to equilibrium condition (c) of Definition 2. Consequently, $f\left(h^{0} \mid z^{*}\right)=s$ must hold, according to (12). Hence, equilibrium market ranges $q^{0}, q^{1}$, and the equilibrium mass of type $h^{0}$ assigned as manager, $\hat{g}\left(h^{0}\right)$, are simultaneously given by (C.7), holding for $k=0,1$, and

$$
\Gamma\left(\frac{a\left(h^{0}\right)^{\sigma-1}\left(1-\hat{g}\left(h^{0}\right)-g\left(h^{1}\right)\right) s}{\left(\hat{g}\left(h^{0}\right) q^{0}+(1-r) q^{1}\right)\left[\hat{g}\left(h^{0}\right) a\left(h^{0}\right)^{\sigma-1}+g\left(h^{1}\right) a\left(h^{1}\right)^{\sigma-1}\right]}\right)^{\frac{\eta}{\eta-1}}=s,
$$

according to (C.6). This must yield $q^{k} \in(0,1)$ for $k=0,1$ and $\hat{g}\left(h^{0}\right) \in(0, g(h))$ to be consistent with the supposed equilibrium. Moreover, in view of (C.6), existence of this equilibrium can be confirmed if $a\left(\bar{h}_{i}\right)^{\frac{(\sigma-1) \eta}{\eta-1}}$ is strictly convex in $\bar{h}_{i}$ at both $\bar{h}_{i}=h^{0}$ and $\bar{h}_{i}=h^{1}$, according to Proposition 3. Thus, we have derived all endogenous variables as functions of the "fundamentals" of the economy: skill endowments $h^{0}$, $h^{1}$ in supply $g\left(h^{0}\right), g\left(h^{1}\right)$, demand parameter $\sigma$, technology parameters $F$ and $\eta$ from specification (C.3), the function $a(\cdot)$ and the size $s$ of head departments. Under 
appropriate assumptions about these fundamentals, the supposed equilibrium exists. According to Proposition 1, $f\left(h^{1} \mid z^{*}\right)>f\left(h^{0} \mid z^{*}\right)$ and $q^{1}>q^{0}$ for gross profits and market ranges, respectively. Wages read $w\left(h^{1}\right)=f\left(h^{1} \mid z^{*}\right) / s>f\left(h^{0} \mid z^{*}\right) / s=$ $w\left(h^{0}\right)=\bar{W}=1$ in this example, according to Proposition 2.

Second, analogously, suppose the configuration of manager assignment is symmetric, i.e., $\bar{h}_{i}^{*}=\bar{h}^{*}$ and, thus, $\alpha_{i}^{*}=a\left(\bar{h}^{*}\right)$ and $q_{i}^{*}=q^{*}$ for all $i \in \mathcal{I}$. For simplicity, let $Q(\cdot) \equiv 0$ such that $q^{*}=1$. Hence, $\Xi_{m}=\Xi^{*}=I^{*} a\left(\bar{h}^{*}\right)^{\sigma-1}$ for all $m$. Again, let there be two skill types $h^{0}$ and $h^{1}, h^{0}<h^{1}$, both types being assigned as manager. Using this together with $q^{*}=1, Q(1)=0$ and $L^{*}=1-\hat{g}\left(h^{0}\right)-g\left(h^{1}\right)$ (labor market clearing), one obtains

$$
f\left(\bar{h}_{i} \mid z^{*}\right)=\frac{a\left(\bar{h}_{i}\right)^{\sigma-1}\left(1-\hat{g}\left(h^{0}\right)-g\left(h^{1}\right)\right)}{\left(\hat{g}\left(h^{0}\right)+g\left(h^{1}\right)\right) a\left(\bar{h}^{*}\right)^{\sigma-1}} \frac{s}{\sigma-1},
$$

according to (3), (6), (17) and (C.1). Thus, we have

$$
f\left(\bar{h}^{*} \mid z^{*}\right)=\frac{1-\hat{g}\left(h^{0}\right)-g\left(h^{1}\right)}{\hat{g}\left(h^{0}\right)+g\left(h^{1}\right)} \frac{s}{\sigma-1}
$$

and

$$
\frac{\partial f\left(\bar{h}^{*} \mid z^{*}\right)}{\partial \bar{h}_{i}}=\frac{1-\hat{g}\left(h^{0}\right)-g\left(h^{1}\right)}{\hat{g}\left(h^{0}\right)+g\left(h^{1}\right)} \frac{a^{\prime}\left(\bar{h}^{*}\right) s}{a\left(\bar{h}^{*}\right)},
$$

respectively, where $\bar{h}^{*}=\frac{h^{0} \hat{g}\left(h^{0}\right)+h^{1} g\left(h^{1}\right)}{\hat{g}\left(h^{0}\right)+g\left(h^{1}\right)}$, according to equation (13). Using equations (14), (C.10) and (C.11), as well as $h^{0}=h^{\min }$ and $w\left(h^{0}\right)=\bar{W}=1, \hat{g}\left(h^{0}\right)$ is given by

$$
\frac{1-\hat{g}\left(h^{0}\right)-g\left(h^{1}\right)}{\hat{g}\left(h^{0}\right)+g\left(h^{1}\right)}\left(\frac{1}{\sigma-1}+\frac{a^{\prime}\left(\bar{h}^{*}\right)}{a\left(\bar{h}^{*}\right)}\left(h^{0}-\bar{h}^{*}\right)\right)=1 .
$$

A symmetric equilibrium exists if this yields $\hat{g}\left(h^{0}\right) \in(0, g(h))$ and $a\left(\bar{h}_{i}\right)^{\sigma-1}$ is strictly concave in $\bar{h}_{i}$ at $\bar{h}_{i}=\bar{h}^{*}$. Finally,

$$
w\left(h^{1}\right)=\frac{1-\hat{g}\left(h^{0}\right)-g\left(h^{1}\right)}{\hat{g}\left(h^{0}\right)+g\left(h^{1}\right)}\left(\frac{1}{\sigma-1}+\frac{a^{\prime}\left(\bar{h}^{*}\right)}{a\left(\bar{h}^{*}\right)}\left(h^{1}-\bar{h}^{*}\right)\right) .
$$

\section{References}

Abowd, John M., Francis Kramarz and David N. Margolis (1999). High Wage Workers and High Wage Firms, Econometrica 67 (2), 251-333. 
Athey, Susan and Armin Schmutzler (2001). Investment and Market Dominance, RAND Journal of Economics 32 (1), 1-26.

Baily, Martin N., Charles Hulten and David Campbell (1992). The Distribution of Productivity in Manufacturing Plants, Brookings Papers of Economic Activity 0, Microeconomics, 187-249.

Bartelsman, Eric J. and Mark Domes (2000). Understanding Productivity: Lessons from Longitudinal Microdata, Journal of Economic Literature 38 (3), 569594.

Berman, Eli, John Bound, and Zvi Grichilis (1994). Changes in the Demand for Skilled Labor Within U.S. Manufacturing: Evidence from the Annual Survey of Manufactures, Quarterly Journal of Economics 109 (2), 367-397.

Bresnahan, Timothy F. (1999). Computerisation and Wage Dispersion: An Analytical Reinterpretation, Economic Journal 109, F390-F415.

Caves, Richard E. (1982). Multinational Enterprise and Economic Analysis (London: Cambridge University Press).

Coase, Ronald (1937). The Nature of the Firm, Economica 4, 386-405.

Conyon, Martin J. and Kevin M. Murphy (2000). The Prince and the Pauper? CEO Pay in the United States and United Kingdom, Economic Journal 110, F640F671.

Dixit, Avinash and Joseph E. Stiglitz (1977). Monopolistic Competition and Optimum Product Diversity, American Economic Review 67, 297-308.

Dunning, John H. (1981). International Production and the Multinational Enterprise (London: Allen and Unwin).

Fishman, Arthur and Rafael Rob (1999). The Size of Firms and R\&D Investment, International Economic Review 40 (4), 915-931.

Grossman, Sanford and Oliver Hart (1986). The Costs and Benefits of Ownership: A Theory of Lateral and Vertical Integration, Journal of Political Economy 94, 691-719.

Grossmann, Volker (2002). Quality Improvements, the Structure of Employment, and the Skill-Bias Hypothesis Revisited, Topics in Macroeconomics 2 (1), 
Article 2, http://www.bepress.com/bejm/topics/vol2/iss1/art2/.

Hart, Oliver and John Moore (1990). Property Rights and the Nature of the Firm, Journal of Political Economy 98, 1119-1158.

Helpman, Elhanan (1981). International Trade in the Presence of Product Differentiation, Economies of Scale and Monopolistic Competition, Journal of International Economics 11, 305-40.

Holmström, Bengt and Paul Milgrom (1991). Multitask Principal-Agent Analyses: Incentive Contracts, Asset Ownership, and Job Design, Journal of Law, Economics, and Organization 7, 24-51.

Holmström, Bengt and Paul Milgrom (1994). The Firm as an Incentive System, American Economic Review 84, 972-991.

Holmström, Bengt and John Roberts (1998). The Boundaries of the Firm Revisited, Journal of Economic Perspectives 12 (4), 73-94.

Hotelling, Harold (1929). Stability in Competition, Economic Journal 39, 41-57.

Jovanovic, Boyan (1982). Selection and the Evolution of Industry, Econometrica $50,649-670$.

Kremer, Michael (1993). The O-Ring Theory of Economic Development, Quarterly Journal of Economics 108 (3), 551-75.

Kremer, Michael and Erik Maskin (1996). Wage Inequality and Segregation by Skill, NBER Working Paper No. 5718.

Lancaster, Kelvin (1979). Variety, Equity, and Efficiency, Columbia University Press.

Lucas, Robert, E. (1978). On the Size Distribution of Business Firms, Bell Journal of Economics 9 (2), 508-523.

Markusen, James R. (1995). The Boundaries of Multinational Enterprises and the Theory of International Trade, Journal of Economic Perspectives 9 (2), 169-189.

Martin, Stephen (1991). Direct Foreign Investment, Journal of Economic Behavior and Organization 16, 283-293.

Morck, Randall and Bernard Yeung (1992). Internationalization: An Event Study Test, Journal of International Economics 33 (1-2), 41-56. 
Ottaviano, Gianmarco I.P. and Jacques-François Thisse (1999). Monopolistic Competiton, Multiproduct Firms and Optimum Product Diversity, CORE Discussion Paper No. 9919.

O'Shaughnessy, K.C., David I. Levine and Peter Capelli (2001). Changes in Managerial Pay Structures 1986-1992 and Rising Returns to Skill, Oxford Economic Papers 3, 482-507.

Porter, Michael E. (1986). Changing Patterns of International Competition, California Management Review 28 (2), 9-40.

Prat, Andrea (2002). Should a Team be Homogenous, European Economic Review 46 (7), 1187-1207.

Roberts, Mark J. and Dylan Supina (2000). Output Price and Markup Dispersion in Producer Micro Data: The Roles of Producer Heterogeneity and Noise, in: Baye, M. (Ed.), Advances in Applied Microeconomics, Vol. 9, Industrial Organization (JAI Press).

Rosen, Sherwin (1981). The Economics of Superstars, American Economic Review 71 (5), 845-858.

Rosen, Sherwin (1982). Authority, Control, and the Distribution of Earnings, Bell Journal of Economics 13 (2), 311-323.

Saint-Paul, Gilles (2001). On the Distribution of Income and Worker Assignment Under Intrafirm Spillovers, with an Application to Ideas and Networks, Journal of Political Economy 109 (1), 1-37.

Salop, Steven C. (1979). Monopolistic Competition with Outside Goods, Bell Journal of Economics 10 (1), 141-56.

Sattinger, Michael (1993). Assignment Models of the Distribution of Earnings, Journal of Economic Literature 31 (2), 831-880.

Salamon, Gerald L. (1985). Accounting Rates of Return, American Economic Review 75, 495-504.

Schmalensee, Richard (1989). Inter-Industry Studies of Structures and Performance, in: Schmalensee, R. and R. Willig (Eds.), Handbook of Industrial Organization, Vol. 2, 951-1009. 
Shaked, Avner and John Sutton (1982). Relaxing Price Competition Through Product Differentiation, Review of Economic Studies 49 (1), 3-13.

Shaked, Avner and John Sutton (1983). Natural Oligopolies, Econometrica 51 (5), 1469-1483.

Shimer, Robert (2001). The Assignment of Workers to Jobs in an Economy with Coordination Frictions, NBER Working Paper No. 8501.

Shimer, Robert and Lones Smith (2000). Assortative Matching and Search, Econometrica 68 (2), 343-370.

Spence, Michael (1976). Product Selection, Fixed Costs, and Monopolistic Competition, Review of Economic Studies 43 (2), 217-35.

Sutton, John (1997). Gibrat's Legacy, Journal of Economic Literature 35 (1), 40-59.

Sutton, John (1998). Technology and Market Structure (Cambridge: MIT Press).

Troske, Kenneth R. (1999). Evidence on the Employer Size-Wage Premium, Review of Economics and Statistics 81 (1), 15-26.

Williamson, Oliver E. (1975). Markets and Hierarchies: Analysis and Antitrust Implications (New York: The Free Press).

Williamson, Oliver E. (1979). Transaction-Cost Economics: The Governance of Contractual Relations, Journal of Law and Economics 22, 233-271.

Williamson, Oliver E. (1985). The Economic Institutions of Capitalism (New York: The Free Press).

Wong, Kar-yiu (1995). International Trade in Goods and Factor Mobility (Cambridge: MIT Press). 


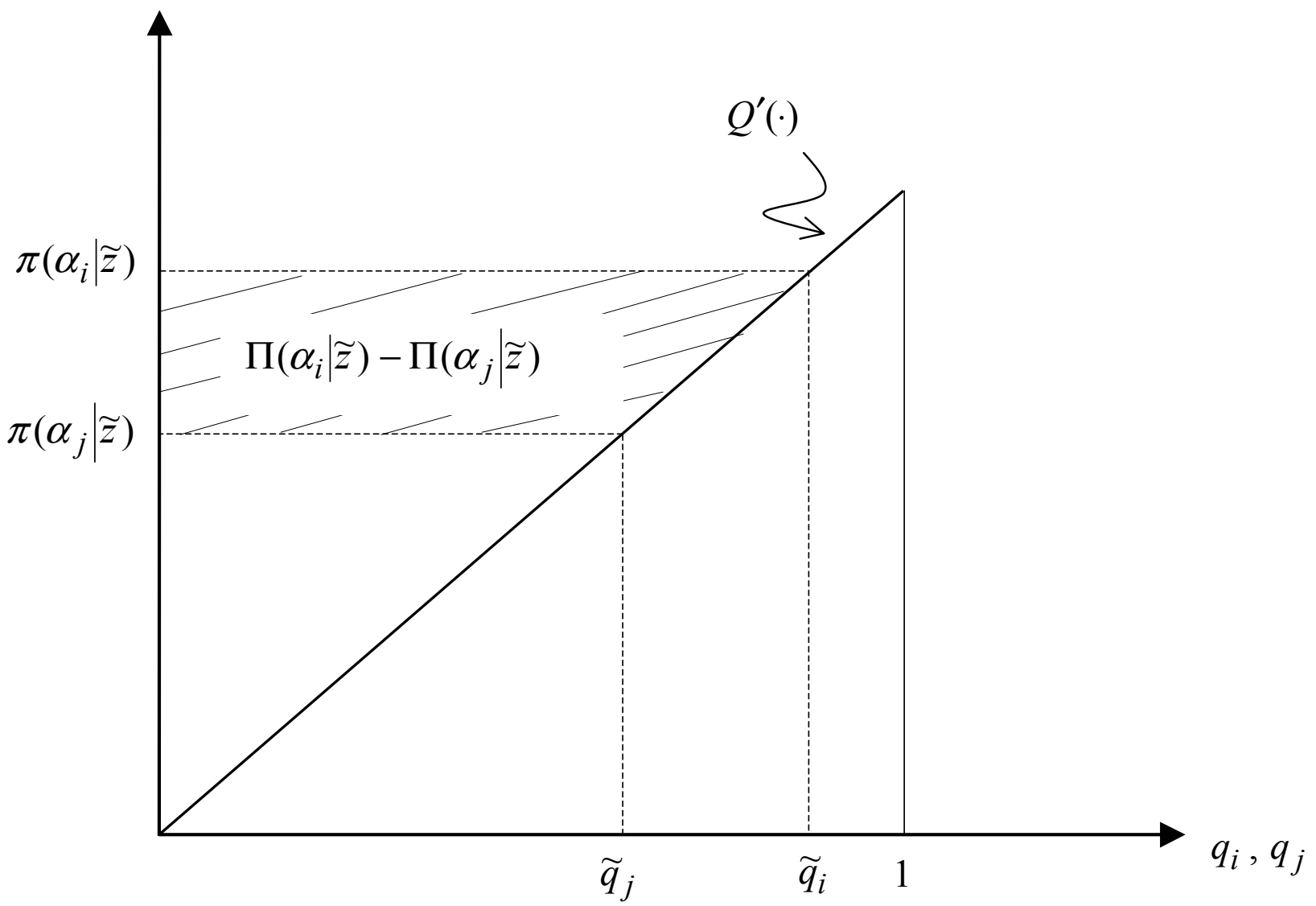

Figure 1: Profits and market ranges of firms $i$ and $j$ if $\alpha_{i}>\alpha_{j}$. 


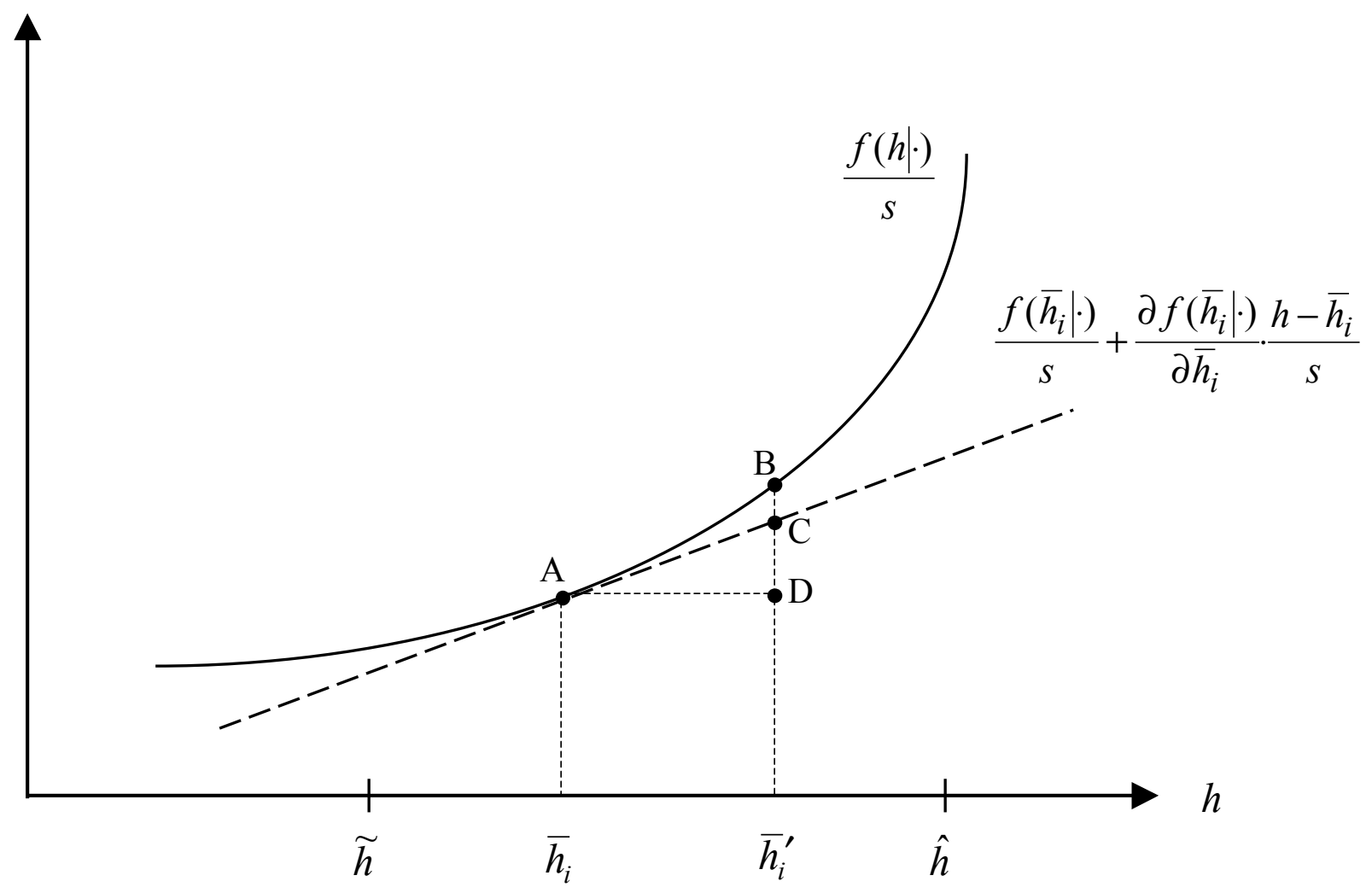

Figure 2: Convexity and segregation by managerial skill. 


\section{IZA Discussion Papers}

\begin{tabular}{|c|c|c|c|c|}
\hline No. & Author(s) & Title & Area & Date \\
\hline 723 & $\begin{array}{l}\text { M. Coles } \\
\text { B. Petrongolo }\end{array}$ & $\begin{array}{l}\text { A Test between Unemployment Theories Using } \\
\text { Matching Data }\end{array}$ & 3 & $02 / 03$ \\
\hline 724 & $\begin{array}{l}\text { J. T. Addison } \\
\text { R. Bailey } \\
\text { W. S. Siebert }\end{array}$ & $\begin{array}{l}\text { The Impact of Deunionisation on Earnings } \\
\text { Dispersion Revisited }\end{array}$ & 2 & $02 / 03$ \\
\hline 725 & S. Habermalz & An Examination of Sheepskin Effects Over Time & 1 & $02 / 03$ \\
\hline 726 & S. Habermalz & $\begin{array}{l}\text { Job Matching and the Returns to Educational } \\
\text { Signals }\end{array}$ & 1 & $02 / 03$ \\
\hline 727 & $\begin{array}{l}\text { M. Raiser } \\
\text { M. Schaffer } \\
\text { J. Schuchardt }\end{array}$ & Benchmarking Structural Change in Transition & 4 & $02 / 03$ \\
\hline 728 & $\begin{array}{l}\text { M. Lechner } \\
\text { J. A. Smith }\end{array}$ & What is the Value Added by Caseworkers? & 6 & $02 / 03$ \\
\hline 729 & $\begin{array}{l}\text { A. Voicu } \\
\text { H. Buddelmeyer }\end{array}$ & $\begin{array}{l}\text { Children and Women's Participation Dynamics: } \\
\text { Transitory and Long-Term Effects }\end{array}$ & 3 & $02 / 03$ \\
\hline 730 & $\begin{array}{l}\text { M. Piva } \\
\text { M. Vivarelli }\end{array}$ & $\begin{array}{l}\text { Innovation and Employment: Evidence from } \\
\text { Italian Microdata }\end{array}$ & 2 & $02 / 03$ \\
\hline 731 & $\begin{array}{l}\text { B. R. Chiswick } \\
\text { N. DebBurman }\end{array}$ & $\begin{array}{l}\text { Educational Attainment: Analysis by Immigrant } \\
\text { Generation }\end{array}$ & 1 & $02 / 03$ \\
\hline 732 & $\begin{array}{l}\text { A. Falk } \\
\text { A. Ichino }\end{array}$ & Clean Evidence on Peer Pressure & 5 & $03 / 03$ \\
\hline 733 & $\begin{array}{l}\text { S. Wolter } \\
\text { S. Denzler }\end{array}$ & $\begin{array}{l}\text { Wage Elasticity of the Teacher Supply in } \\
\text { Switzerland }\end{array}$ & 2 & $03 / 03$ \\
\hline 734 & S. Wolter & Sibling Rivalry: A Six Country Comparison & 2 & $03 / 03$ \\
\hline 735 & $\begin{array}{l}\text { R. Desmet } \\
\text { A. Jousten } \\
\text { S. Perelman } \\
\text { P. Pestieau }\end{array}$ & $\begin{array}{l}\text { Micro-Simulation of Social Security Reforms in } \\
\text { Belgium }\end{array}$ & 3 & $03 / 03$ \\
\hline 736 & $\begin{array}{l}\text { I. Bolvig } \\
\text { P. Jensen } \\
\text { M. Rosholm }\end{array}$ & The Employment Effects of Active Social Policy & 6 & $03 / 03$ \\
\hline 737 & $\begin{array}{l}\text { A. L. Booth } \\
\text { M. Francesconi } \\
\text { G. Zoega }\end{array}$ & $\begin{array}{l}\text { Unions, Work-Related Training, and Wages: } \\
\text { Evidence for British Men }\end{array}$ & 3 & $03 / 03$ \\
\hline 738 & V. Grossmann & $\begin{array}{l}\text { Managerial Job Assignment and Imperfect } \\
\text { Competition in Asymmetric Equilibrium }\end{array}$ & 1 & $03 / 03$ \\
\hline
\end{tabular}

An updated list of IZA Discussion Papers is available on the center's homepage www.iza.org. 